\title{
Thermodynamically Informed Nuclear Fuel Codes-A Review and Perspectives
}

\author{
Markus H. A. Piro
}

check for updates

Citation: Piro, M.H.A

Thermodynamically Informed Nuclear Fuel Codes-A Review and Perspectives. Thermo 2021, 1, 262-285. https://doi.org/10.3390/ thermo1020018

Academic Editor: Ondřej Beneš

Received: 12 July 2021

Accepted: 3 September 2021

Published: 9 September 2021

Publisher's Note: MDPI stays neutral with regard to jurisdictional claims in published maps and institutional affiliations.

Copyright: (C) 2021 by the author. Licensee MDPI, Basel, Switzerland. This article is an open access article distributed under the terms and conditions of the Creative Commons Attribution (CC BY) license (https:/ / creativecommons.org/licenses/by/ $4.0 /)$.
Faculty of Energy Systems and Nuclear Science, Ontario Tech University, Oshawa, ON L1G 0C5, Canada; markus.piro@ontariotechu.ca

\begin{abstract}
A number of codes are used to predict various aspects of nuclear fuel performance and safety, ranging from conventional fuel performance codes to simulate normal operating conditions to integral engineering codes to simulate severe accident behaviour. There has been a number of reportings in the open literature of nuclear fuel codes being informed by thermodynamic calculations, ranging from the use of simple thermodynamic correlations to direct coupling of equilibrium thermodynamic software. Progress in expanding predictive capabilities have been reported, which also includes advances in thermodynamic database development to better capture irradiated fuel. However, this progress has been accompanied by several challenges, including effective coupling of different types of physical phenomena in a practical manner and doing so with a reasonable increase in computational expense. This review paper will summarize previous experiences reported in the open literature in coupling thermodynamic calculations with nuclear fuel codes and applications, identify current challenges and limitations, and offer some perspectives for the community to consider moving forward.
\end{abstract}

Keywords: thermodynamics; nuclear fuel; fuel performance; fuel safety; multi-physics; CALPHAD

\section{Introduction}

Nuclear fuel codes are used to predict various aspects of nuclear reactor operation to support research and development, engineering design, operation, safety, and licensing activities. One can partition the large number of fuel codes into two broad classes based on their intended application (this classification system is not standardized but is used in this manuscript for sake of convenience and clarity): Class I: research and development, and Class II: fuel performance and safety analyses for industry ranging from Normal Operating Conditions (NOC) to Severe Accidents (SA).

Class I codes used for research and development purposes are broadly aimed at capability development, phenomena exploration, knowledge gap identification, and interpretation of experimental findings. A number of codes in Class II are used by industry and regulators to inform the design, operation, safety, and licensing of nuclear fuels, which requires a high degree of Quality Assurance (QA). While QA requirements are absolutely necessary to inform the decision making pertaining to safety and licensing, they are not conducive to software capability development or exploratory activities. The primary objective of nuclear fuel codes in Class I is to advance and explore various computational and predictive capabilities of nuclear fuel behaviour as a research and development tool, which may or may not be incorporated in a Class II toolset at a later time. Furthermore, the flexibility of Class I codes makes them conducive to knowledge gap identification, which may be helpful to provide guidance to future separate effects experiments.

Class II codes are considered here as nuclear fuel performance and safety codes used specifically by industry and regulators to inform engineering design, qualification, safety, and licensing. There has been a plethora of codes developed and qualified for specific nuclear fuel designs. Traditionally, fuel performance codes are used by industry to simulate fuel behaviour under NOC. These codes typically solve a coupled system of equations 
representing heat transfer, mechanical deformation, and fission product behaviour with the principle objective of predicting temperature, strain, and fission gas release under NOC. Other safety analysis toolsets typically simulate various behaviours of the fuel under design basis accidents, beyond design basis accidents, and SA conditions. Specific phenomena that may be simulated include fuel oxidation under defective conditions, source term analyses, fuel melting, and fuel volatilization. Most of these codes are considered engineering scale integral codes, which must meet high levels of QA due to their intended application to support nuclear safety analyses.

In both classes of nuclear fuel codes, some cases have been reported in the open literature where the analyses have been informed by thermodynamic calculations, which include look-up tables of gaseous partial pressures, simple empirical correlations, and direct coupling with an equilibrium thermodynamics solver. The majority of these thermodynamic calculations are based on thermodynamic models derived with the CALPHAD method [1]. This method broadly refers to a methodical technique to derive thermodynamic models based on experimental data, such as heat capacity, enthalpy of mixing, chemical potentials, phase transition temperatures, etc. Here, the term 'model' corresponds to a particular phase whereby the collection of models pertaining to a system is referred to as a 'treatment'. The assemblage of many treatments in an organized manner constitutes a 'database'. The development of these models with the CALPHAD technique can be used to generate phase diagrams of binary and ternary systems, perform point equilibrium calculations, and several other applications of equilibrium thermodynamics of practical interest to industry.

Thermodynamic treatments of various systems derived with the CALPHAD method can be solved with a Gibbs Energy Minimizer (GEM), which typically use the method of undetermined Lagrangian multipliers to minimize the integral Gibbs energy of a system subject to appropriate constraints [2]. Some commercial thermodynamic software packages include FACTSAGE [3] and THERMOCALC [4], and some open-source packages include PYCALPHAD [5], OPENCALPHAD [6], and THERMOCHIMICA [7]. The interested reader is referred to the work of Lukas et al. [8], Hillert [9], Liu et al. [10], and Pelton [11] on more specific topics related to CALPHAD. A review of computational thermodynamics specific to nuclear materials is given by Guéneau et al. [12,13].

The level of fidelity of thermodynamic analyses informing nuclear fuel codes reviewed in this article varies greatly. For some applications discussed herein, material systems are well captured by thermodynamic models, while others have large knowledge gaps and/or are represented by models that by today's standards may seem primitive. What is important to understand is that while the field of thermodynamics has importance to nuclear fuels, there are other disciplines that are also important to assess reactor behaviour (e.g., thermalhydraulics, reactor physics). In some circumstances, a model that may appear to be crude, may be sufficient and appropriate given its importance and impact on predicting the reactor system's behaviour. Nevertheless, there has been tremendous progress in understanding the thermodynamics of irradiated fuel and fission product chemistry over the past few decades. The number and quality of experiments has improved greatly, as have databases.

The primary objective of this review article is to survey the open literature on experiences reported in thermodynamic calculations informing both classes of nuclear fuel codes and to assess its value, utility, and potential areas of improvement in future activities. A review of Class I research and development codes is given in Section 2, Class II industrial nuclear fuel performance and safety codes in Section 3, and a discussion with perspectives is offered in Section 4. Table 1 gives an overview of these codes, which will be referred to throughout this manuscript. 
Table 1. A summary of relevant codes mentioned in this article. GEM = Gibbs Energy Minimization.

\begin{tabular}{cccc}
\hline Code Name & Primary Application & Coupling Method & Ref. \\
\hline ALCYONE & Class I & ANGE, OPENCALPHAD & {$[14]$} \\
AMP & Class I & THERMOCHIMICA & {$[15]$} \\
ANGE & GEM & Empirical correlations & {$[16]$} \\
ASTEC & Class II & THERMOCHIMICA & {$[18]$} \\
BISON & Class I & & {$[19]$} \\
CHEMAPP & GEM & Simplified model & {$[20]$} \\
COMSOL & Class I & & {$[3]$} \\
FACTSAGE & GEM & ANGE, OpENCALPHAD & {$[14]$} \\
GERMINAL & Class I & Simplified model; Look-up table & {$[21]$} \\
MARMOT & Class I & GEM (unknown) & {$[22]$} \\
MELCOR & Class II & Unknown & {$[23]$} \\
MFPR & Class II & & {$[6]$} \\
OPENCALPHAD & GEM & & {$[5]$} \\
PYCALPHAD & GEM & & {$[24]$} \\
SOLGASMIX & GEM & Empirical correlations & {$[25]$} \\
SOURCE & Class II & & {$[4]$} \\
THERMOCALC & GEM & Unknown & {$[7]$} \\
THERMOCHIMICA & GEM & & {$[26]$} \\
VICTORIA & Class II & & \\
\hline
\end{tabular}

\section{Class I: Research and Development Fuel Codes}

Several activities have been reported in the open literature in the research and development of nuclear fuel codes that have been informed by thermodynamic calculations. Focus will be given to analyses that have used some type of thermodynamic description of the fuel or other system as input. This section is partitioned based on experiences reported in the open literature regarding the following fuel codes: COMSOL in Section 2.1, AMP in Section 2.2, BISON in Section 2.3, MARMOT in Section 2.4, ALCYONE in Section 2.5, and GERMINAL in Section 2.6.

\subsection{COMSOL}

Several computational campaigns using the commercial multi-physics software COMSOL to simulate $\mathrm{UO}_{2}$ nuclear fuel behaviour that were informed by thermodynamic quantities have been reported in the literature. Higgs et al. presented work that simulated fuel oxidation under defective conditions, whereby the cladding has failed and coolant water has come into direct contact with the fuel [27]. Fuel oxidation was informed by a simplified thermodynamic correlation often referred to as the "Lindemer-Besmann equation" [28]. Interstitial oxygen transport was handled by solving Fickian diffusion equations along with a thermodynamically informed correlation between composition, temperature, and oxygen partial pressure [27]. Furthermore, a simplified correlation was proposed by Higgs et al. for the compositional dependence of $x$ in $\mathrm{UO}_{2+x}$ [27]. These calculations were also coupled with heat conduction equations, gas phase transport in the fuel-clad gap, and gas phase transport in fuel cracks [27]. Simulation predictions compared reasonably well to defective fuel experiments at the Chalk River Laboratories (Canada), although there were some noticeable differences in some situations [27]. While the simulation framework was rather impressive, the source of the discrepancy remains unclear and is likely a combination of experimental conditions that could have been better controlled and some physical phenomena better captured in the simulation work.

Welland et al. have also reported experience using COMSOL to simulate non-congruent melting of $\mathrm{UO}_{2+x}$ under abnormal conditions [29]. A phase field approach was incorporated into COMSOL, which solved heat conduction, solid state diffusion of oxygen, and the rate of phase change [29]. Several material properties were dependent on both temperature and composition, such as heat capacity, enthalpy, and thermal conductivity [29]. Phase 
transformations incorporated Gibbs energy equations of both solid and liquid $\mathrm{UO}_{2+x}$ that were derived using the CALPHAD approach with respect to laser flash melting experiments at the Joint Research Centre (JRC)-Karlsruhe [30]. To maintain a self-consistent description of the fuel, the heat capacity, enthalpy, and Gibbs energy were all derived from the same set of equations [31]. This phase field simulation framework compared very well to time-dependent data recorded from a set of laser flash experiments at JRC.

The phase field computational framework to simulate non-congruent melting of $\mathrm{UO}_{2+x}$ from Welland et al. [29] was later extended to MOX fuel by Böhler et al. [32]. The phase field simulations in COMSOL were used to help interpret melting experiments of MOX fuel using a laser flash facility at JRC [33]. Phase field simulations were helpful in identifying an area of improvement in the laser flash experimental process, specifically in preheating the specimen prior to melting to prevent cracking under a rapid and large thermal gradient [32].

\subsection{AMP}

The Advanced Multi-Physics (AMP) code [15] was developed as a next-generation nuclear fuel code aimed at multi-physics coupling to enhance predictive capabilities of nuclear fuel behaviour. While the AMP code is no longer under development, it is worth noting experiences reported in coupling AMP with ORIGEN-S [34], and THERMOCHIMICA [35]. ORIGEN-S is a code that is part of the SCALE [36] toolset, which solves isotopic depletion, decay, and transmutation calculations. THERMOCHIMICA is an open-source thermochemical equilibrium software library that was designed for direct integration into multi-physics nuclear codes.

In that work, AMP solved heat transfer on a 3D mesh representing Pressurized Water Reactor (PWR) fuel and called ORIGEN-S and THERMOCHIMICA at every node. The power history was provided as input to AMP, which represented the linear power of the fuel. AMP applied a conventional neutron flux depression model to the radial power profile, which experienced a feedback loop with ORIGEN-S to account for the increased local changes in power, such as the increased fission of $\mathrm{Pu}-239$ in the rim region (i.e., the rim effect) [35]. Spatial and temporal changes in the fission product inventory and temperature provided direct input to THERMOCHIMICA, which used the Royal Military College of Canada Thermochemical Treatment [37] to solve local thermodynamic values. With this framework, phase quantities, the oxygen-to-metal ratio in the fluorite phase, oxygen chemical potentials, and other thermodynamic quantities could be predicted in space and time. Mass transport was not simulated.

One interesting prediction from this work was the non-convex variation in the relative oxygen potential (i.e., $R T \ln \left(p_{\mathrm{O}_{2}}\right)$ ) along the radial direction of the fuel, which is shown in Figure 1 [35]. The reason for this non-convex behaviour is due to two competing contributors to the oxygen chemical potential: temperature and local burnup. Near the rim region (i.e., $0.93<r / r_{0}<1.00$ ), the local power and corresponding fission product inventory changes markedly compared to the bulk of the fuel due to the rim effect. This conspicuous change in elemental composition contributes to increasing the relative oxygen potential near the rim, whereas the temperature profile yields the opposite effect. Since oxygen solid-state diffusion in a multi-component system is driven by the oxygen potential gradient, which was not simulated in this work, one could speculate that this non-convex curvature may contribute to some oxygen migrating to the fuel surface. If true, this may potentially contribute to some beneficial passivisation barrier to protect the inner surface of the Zr-alloy cladding from Pellet Cladding Interaction (PCI) [38]. This mechanism may help explain the formation of zirconium oxide on the inner surface of the cladding following fuel-clad gap closure, which is often observed in irradiated fuel. While this point remains speculative, this experience demonstrates how multi-physics simulations may serve as a vehicle for knowledge gap identification and gaining a greater understanding of a problem of practical interest to industry. 


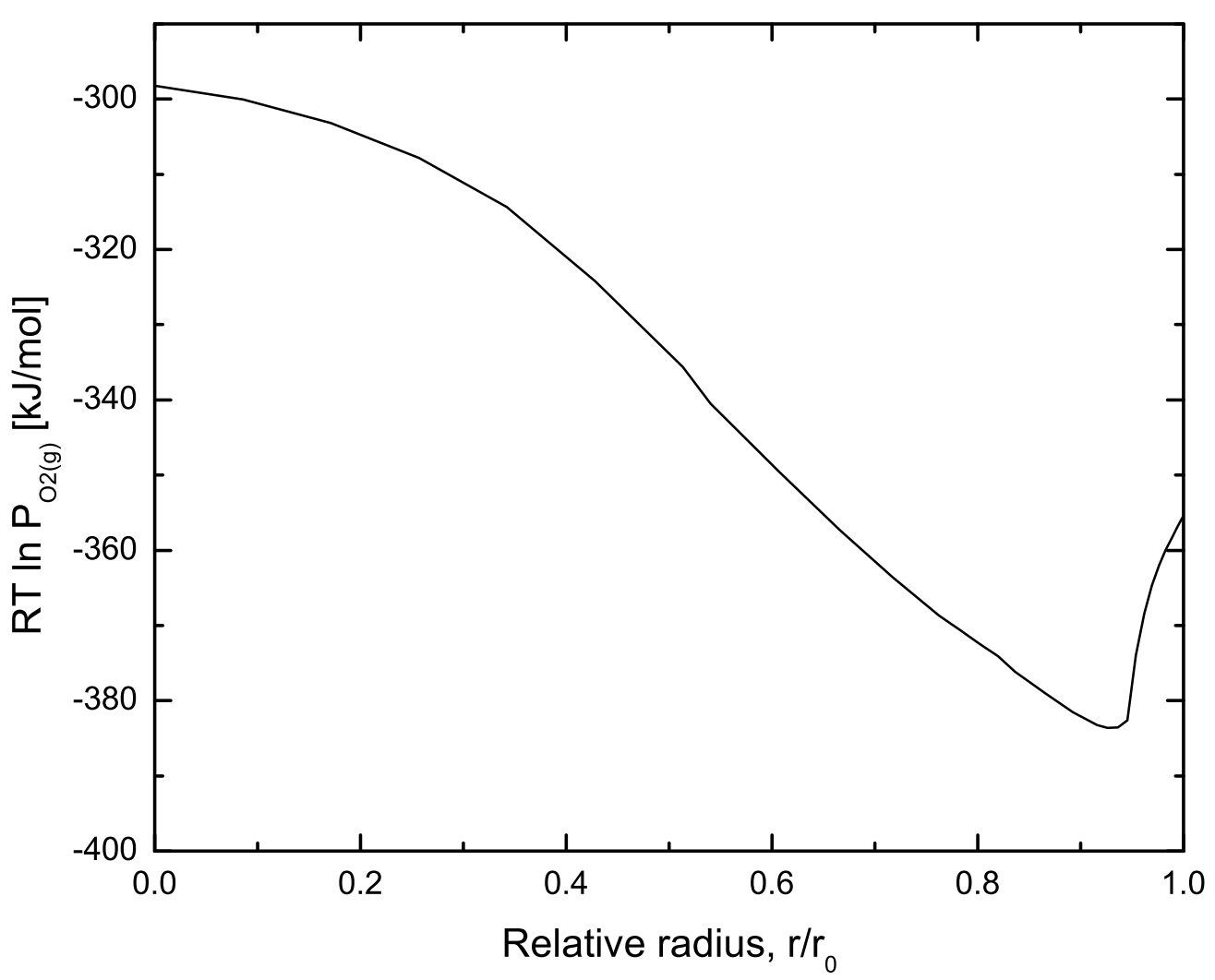

Figure 1. The predicted radial variation of the relative oxygen potential of high burnup PWR fuel from Piro et al. [35].

\subsection{BISON}

BISON [18] is a nuclear fuel performance code that was developed on the MOOSE [39] computational framework. The flexibility and versatility of MOOSE facilitates rapid software development efforts, including predictive capability development in BISON. Here, the discussion will focus solely on thermodynamic coupling with BISON, which will be partitioned in individual subsections based on the following fuel technologies: $\mathrm{UO}_{2}$ oxide fuel (Section 2.3.1) and U-Pu-Zr metallic fuel (Section 2.3.2). Most of the experience with thermodynamic coupling with BISON is with the THERMOCHIMICA code [7,31].

\subsubsection{BISON Simulations of $\mathrm{UO}_{2}$ Oxide Fuel}

Simunovic et al. have reported progress in coupling THERMOCHIMICA with BISON with the principal objective of simulating solid-state diffusion of oxygen in $\mathrm{UO}_{2 \pm x}$ in a manner that is directly informed by thermodynamic calculations [40]. The work described in Section 2.2 gave impetus to this work. Instead of simulating oxygen diffusion driven by concentration gradients of oxygen via the conventional Fickian diffusion methodology, a more fundamental approach involving chemical potential gradients was used, which were calculated directly from Calphad models with multiple sublattices [40]. The conventional use of concentration gradients is typically used for sake of convenience, which also requires a correction for the Soret effect that becomes more prevalent at higher temperatures. Moreover, there are challenges with applying concentration gradient terms to multi-component systems corresponding to fission products. Through the approach established by Simunovic et al. [40], a correction is not needed for the Soret effect. Furthermore, since the approach is general, one can easily extend it to multi-component systems, which enables oxygen diffusion calculations to account for the effects of fission product chemistry [40].

As a demonstration problem, Simunovic et al. considered a PWR fuel pellet with fission products corresponding to a static burnup using the aforementioned coupling 
scheme. Figure 2 illustrates how the oxygen chemical potential in the fuel varies with both space and time. For this demonstration, burnup is maintained constant and the fuel experiences an imposed temperature gradient to demonstrate how oxygen redistributes under a gradient of oxygen potential. At time zero, the distribution of oxygen across the fuel is uniform and the oxygen potential curve varies across the radius solely due to the thermal gradient (i.e., minimum at centre, maximum at periphery). After several months, the oxygen potential curve flattens, which is to be expected as oxygen redistributes within the fuel (see Figure 3) and the system reaches steady-state. As shown in Figure 3, O/M is nearly stoichiometric at the pellet periphery and reaches a maximum at the centre.

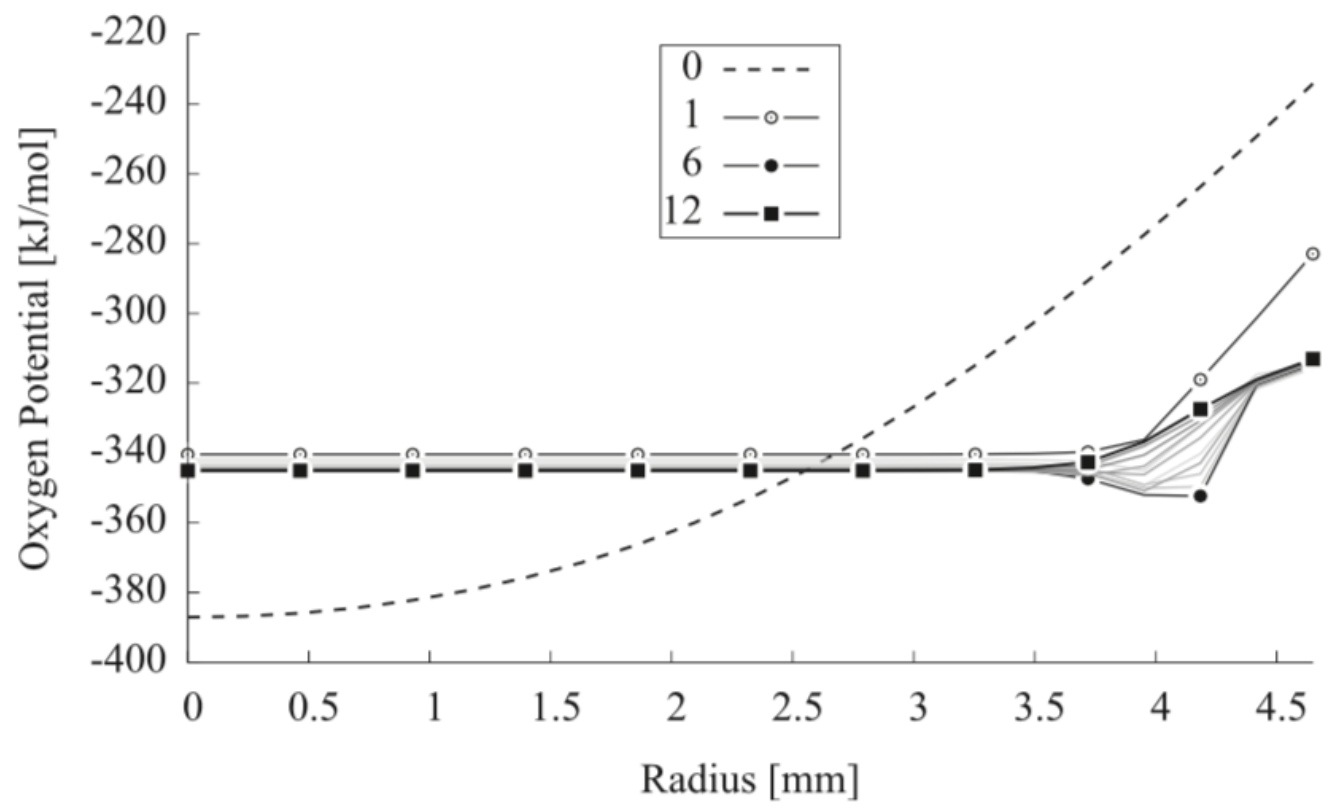

Figure 2. The predicted oxygen chemical potential across the radius of a PWR fuel pellet by Simunovic et al. is shown at different time intervals (months) [40].

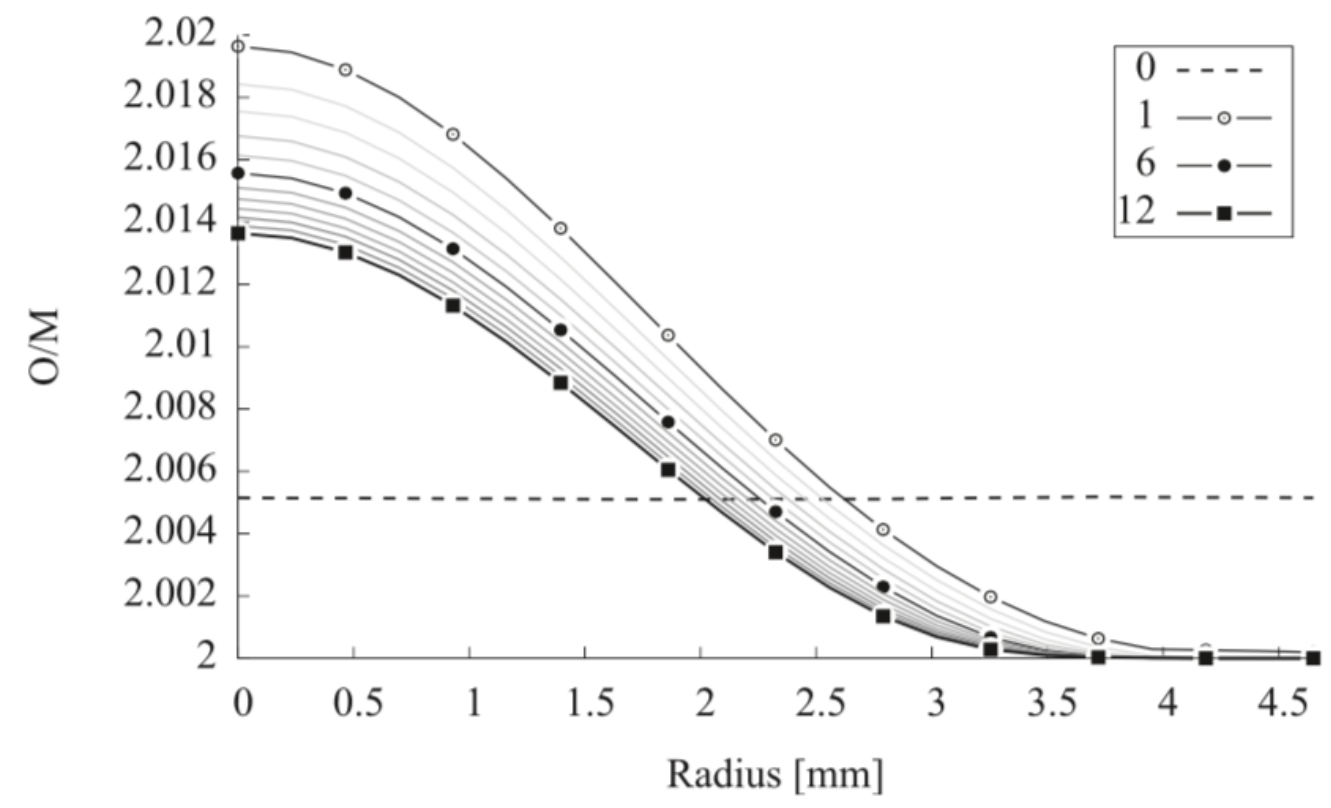

Figure 3. The predicted oxygen-to-metal ratio in the fluorite phase across the radius of a PWR fuel pellet by Simunovic et al. is shown at different time intervals [40]. 
One challenge reported by Simunovic et al. was the marked increase in computational expense associated with performing a large number of thermodynamic equilibrium calculations within BISON [40]. Efforts were made by Poschmann et al. in improving computational performance of THERMOCHIMICA when coupled with BISON [41]. This was achieved by storing the results from THERMOCHIMICA at every single node for a particular time step, which is used as a starting point for each node in the subsequent time step [41]. As reported by Poschmann et al., this re-initialization scheme improved computational performance by one to two orders of magnitude for a number of problems, including irradiated $\mathrm{UO}_{2}$ fuel with up to 22 fission products and molten salt FLiBe with $\mathrm{UF}_{4}$ and 6 fission products [42].

\subsubsection{BISON Simulations of U-Pu-Zr Metallic Fuel}

Poschmann et al. [43] further extended the BISON-THERMOCHIMICA work from Simunovic et al. [40] on irradiated $\mathrm{UO}_{2}$ oxide fuel to irradiated $\mathrm{U}-\mathrm{Pu}-\mathrm{Zr}$ metallic fuel. One principle distinction in the latter campaign is that both $\mathrm{U}$ and $\mathrm{Zr}$ were simulated to interdiffuse [43], whereas only oxygen was simulated to diffuse in the former case [40]. Furthermore, metallic fuel appears to experience significant phase transformations under normal operating conditions, whereby an orthorhombic alpha phase is stable at low temperatures while a body centred cubic gamma phase is predominant at higher temperatures [43]. Due to these marked transformations in $\mathrm{U}$ and $\mathrm{Zr}$ bearing phases, the transport properties of both $\mathrm{U}$ and $\mathrm{Zr}$ were made phase dependent (i.e., $D_{0}$ and $Q$ ); however, not all of those transport properties were well known or known at all [43].

Figure 4 illustrates the predicted distribution of $\mathrm{U}$ and $\mathrm{Zr}$ in fresh $\mathrm{U}-\mathrm{Pu}-\mathrm{Zr}$ fuel and irradiated $\mathrm{U}-\mathrm{Pu}-\mathrm{Zr}$ with comparison to post-irradiation examination measurements from Kim et al. [44]. Clearly, the effects of fuel irradiation have a considerable impact on $U$ and $\mathrm{Zr}$ interdiffusion calculations [43]. In both cases, the typical 'bathtub' profile in $\mathrm{Zr}$ content is observed and the simulation results from the irradiated case is closer to that of the Post Irradiation Examination (PIE) results from Kim et al. [44] than was the case for fresh fuel. There also appears to be some artefacts of the simulation results that appear odd and perhaps physically unrealistic, such as the full depletion of $\mathrm{Zr}$ predicted around $0.4<r / R<0.56$. It is possible that the thermodynamic database may need to be improved to better capture $\mathrm{Zr}$ solubility in various phases and/or transport models that are informed by well executed experiments.

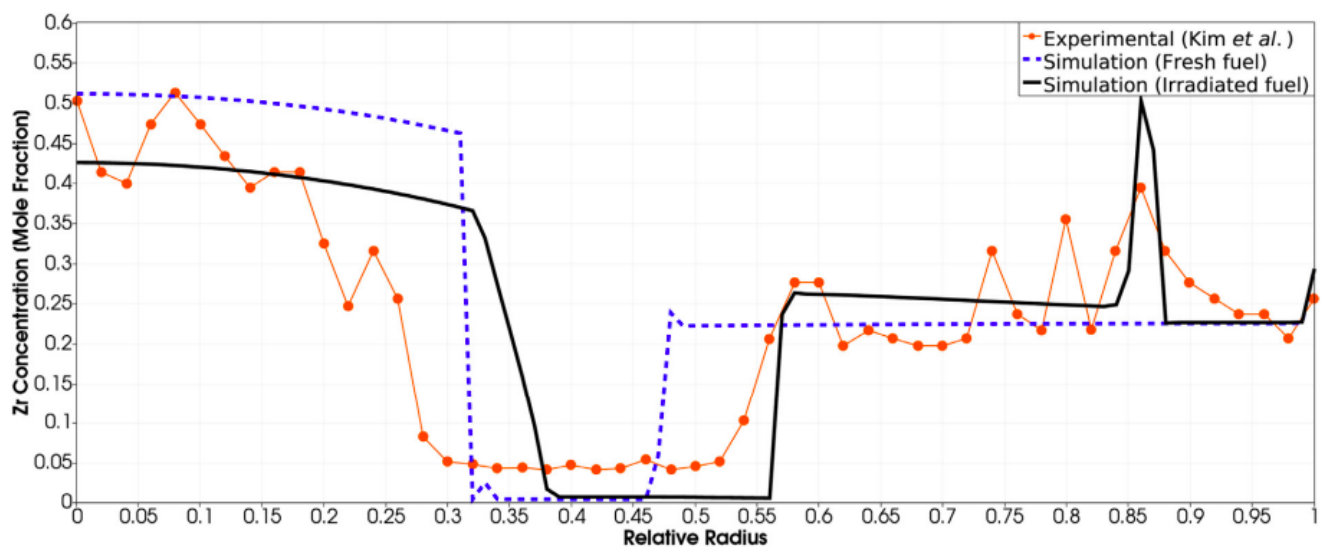

Figure 4. The predicted distribution of $\mathrm{Zr}$ is plotted when assuming fresh $\mathrm{U}-\mathrm{Pu}-\mathrm{Zr}$ fuel and irradiated fuel according to Poschmann et al. [43] with comparisons made to post-irradiation examination experiments from Kim et al. [44].

Similar efforts have been reported by Hirschhorn et al. in simulating $\mathrm{Zr}$ distribution in BISON using a phase field approach with thermodynamic calculations as input [45]. One challenge that was reported by Hirschhorn et al. was the ability to incorporate a thermodynamic representation of five phases (i.e., $\alpha, \beta, \gamma, \delta$, and $\zeta$ ) with three chemical 
elements (i.e., $\mathrm{U}, \mathrm{Pu}$, and $\mathrm{Zr}$ ), which results in an under-determined system with a greater number of unknowns than constraints [45]. To address this issue, the Gibbs energy minimization software PYCALPHAD [5] was used to compute a series of look-up tables that were evaluated by BISON. The thermodynamic calculations were coupled with a phase kinetics model that was empirically calibrated with respect to PIE data (see Figure 5) [45]. The calibrated model worked very well for U-Zr fuel, but had some limitations when applied to U-Pu-Zr fuel [45].

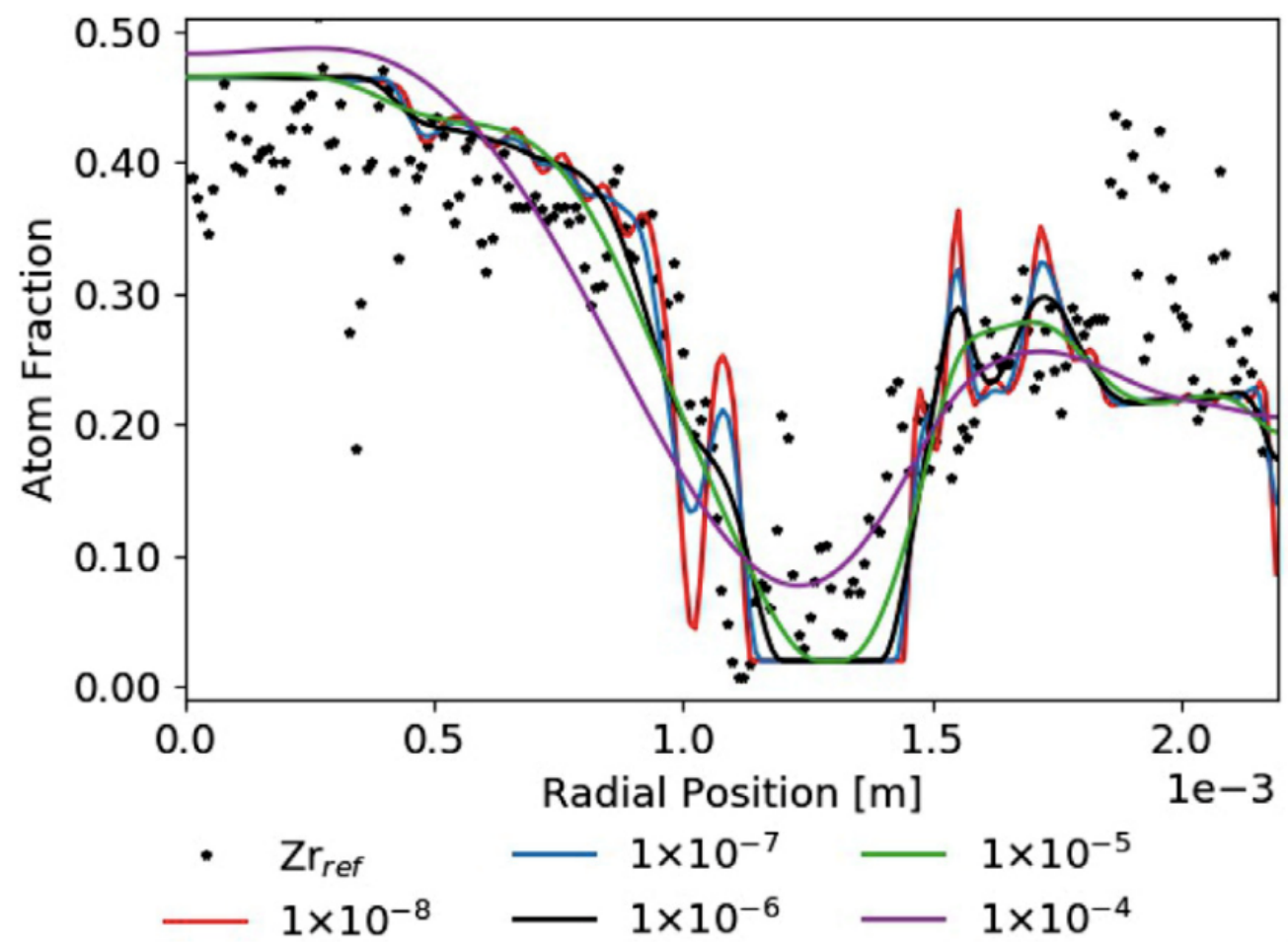

Figure 5. Radial Zr profile of metallic fuel with different tunable parameters, as reported by Hirschhorn et al. [45].

Clearly, there are both strengths and weaknesses of both works from Poschmann et al. [42] and Hirschhorn et al. [45]. The former case was able to better capture the thermochemistry of the fuel, including fission product chemistry of irradiated fuel; however, it did not capture phase kinetics. The work from Hirschhorn et al. was able to capture phase kinetics through a phase field approach; however, it was not able to capture the effects of fission products on fuel chemistry. Perhaps a combined approach may be worthwhile whereby a phase field simulation were used to capture time-dependent phenomena and thermodynamic quantities were provided by THERMOCHIMICA.

\subsection{MARMOT}

MARMOT [21] is a state-of-the-art mesoscale code primarily developed at the Idaho National Laboratory. Similar to BISON, MARMOT is based on the MOOSE multi-physics framework. MARMOT simulates the evolution of microstructure in various solid materials, which has been extensively applied to nuclear fuels and other materials. Some example applications include predicting the thermal conductivity of $\mathrm{HBS}$ regions in $\mathrm{UO}_{2}$ fuel [46], intergranular fission gas diffusion in $\mathrm{U}_{3} \mathrm{Si}_{2}$ fuel [47], and simulating the effects of radiation damage [48]. MARMOT has been helpful in interpreting experimental observations of nuclear fuel and also in developing hierarchical models, such as mechanistic based fission gas models [49].

MARMOT solves a coupled system of non-linear equations corresponding to heat transfer, solid mechanics, and the phase field equations themselves. For the latter, thermo- 
dynamic quantities are required as input, specifically the bulk Gibbs energy of different phases of the system. Since MARMOT is a meso-scale code, lower-length scale local contributions (e.g., interfacial effects) to the Gibbs energy of individual phases also apply [21]. There have been different approaches to incorporating Gibbs energy terms into MARMOT, including fitting simplified polynomial equations to a complex set of equations representing a CALPHAD model, using look-up tables [45], or direct use of Gibbs energy equations.

Progress has been made in MARMOT in implementing an automatic differentiation routine that permits a modular Gibbs energy approach to inform phase field simulations [50]. In this implementation, the Gibbs energy equations are entered by the user in a general form that are interpreted by the software using an automatic symbolic differential capability. Through this approach, user error is reduced as all thermodynamic derivatives (e.g., chemical potentials) are automatically computed by the software. As demonstrated by Schwen et al., this approach has worked well for such problems as spinodal decomposition of Fe-Cr alloys [50].

A principal challenge to direct use of Gibbs energy equations from a CALPHAD model in a phase field simulation, which is not specific to MARMOT, is that the number of species (i.e., unknown variables) is often greater than the number of chemical elements (i.e., constraints due to mass conservation), yielding an under-determined system. For example, the $\mathrm{UO}_{2 \pm x}$ model from Guéneau et al. [51] uses twelve species (or 'compound end members') to represent the phase with three system components (i.e., $\mathrm{U}, \mathrm{O}$, and the electron (the electron in this context corresponds to ionic species and the requirement to respect charge neutrality)). Solving a system with this type of phase is trivial for most GEM codes; however, it would be mathematically impossible to solve in a phase field code without a GEM code because the system would be under-determined. Efforts are currently underway to develop this capability, which is called YELLOWJACKET [52], and is intended for direct coupling to MARMOT. However, concerns remain in regards to the foreseeable increase in computational expense with direct coupling of a phase field code with a GEM solver and whether it is necessary to have direct coupling or if a simplified approach is more appropriate.

\subsection{ALCYONE}

ALCYONE is a nuclear fuel performance code co-developed by CEA, EDF, and AREVA/ Framatome intended for PWRs [53]. It is primarily aimed at simulating fuel during base irradiations, power ramps, and some accident scenarios [54]. Some specific cases that ALCYONE is used to simulate include PCI, Reactivity Initiated Accidents (RIA), and Loss of Coolant Accidents (LOCA) [54]. It is based on the PLEIADES platform with neutronics capabilities from PRODHEL [55], fission gas release from MARGARET [56], and others. ALCYONE serves roles in both Class I and Class II, where it is mainly used for research purposes, but it is used by industry to support licensing on occasion when features in 1.5D codes (e.g., CYRANO [57] or GALILEO [58]) are unavailable.

Early developments of ALCYONE included the capability of capturing thermochemistry via the ANGE module, which was a derivative of the open-source SOLGASMIX software developed by Eriksson [59]. The primary application of this coupling was to inform PCI simulations, including the speciation of various volatile fission products [16]. The TBASE database used in that analysis included an ideal gas, numerous stoichiometric solid phases, the $\mathrm{UO}_{2}$ solid solution phase with dilute fission products, and a model for the noble metals [60,61].

While this development made great progress in PCI simulations, there were some identified limitations in the TBASE thermodynamic database used by ANGE. For instance, phase diagrams of various binary systems generated from this database could not accurately replicate experimental findings. Introïi et al. further advanced the capabilities within ALCYONE by coupling it with the open-source thermochemistry software OPENCALPHAD [6] to improve the handling of thermochemistry [62]. The primary motivation of this work was to leverage the much more complete Thermodynamics for Advanced Fuels-International 
Database (TAF-ID) database [63]. The TAF-ID is a sophisticated thermodynamic database, primarily aimed at $\mathrm{UO}_{2}$ fuel, which has been coordinated by the Organization for Economic Co-operative Development Nuclear Energy Agency (OECD-NEA). The TAF-ID has involved six NEA member states: Canada, European Commission, France, Japan, The Netherlands, Republic of Korea, and the United States. Version 11 of the database, which was used in this analysis, contained 210 assessed binary systems and 76 assessed ternary systems [63].

Figure 6 from Michel et al. [14] gives an example of the distribution of CsI(g) in $\mathrm{UO}_{2}$ fuel during a transient event predicted by ALCYONE coupled with OPENCALPHAD. Thermochemical predictions may be important to predict the availability of iodine to chemically attack the zirconium cladding, including the formation of the stable compound CsI. As reported by Michel et al., another important phenomena to simulate when coupling thermodynamic calculations is oxygen thermodiffusion, whereby the redistribution of oxygen has an important effect on local fission gas release [14].

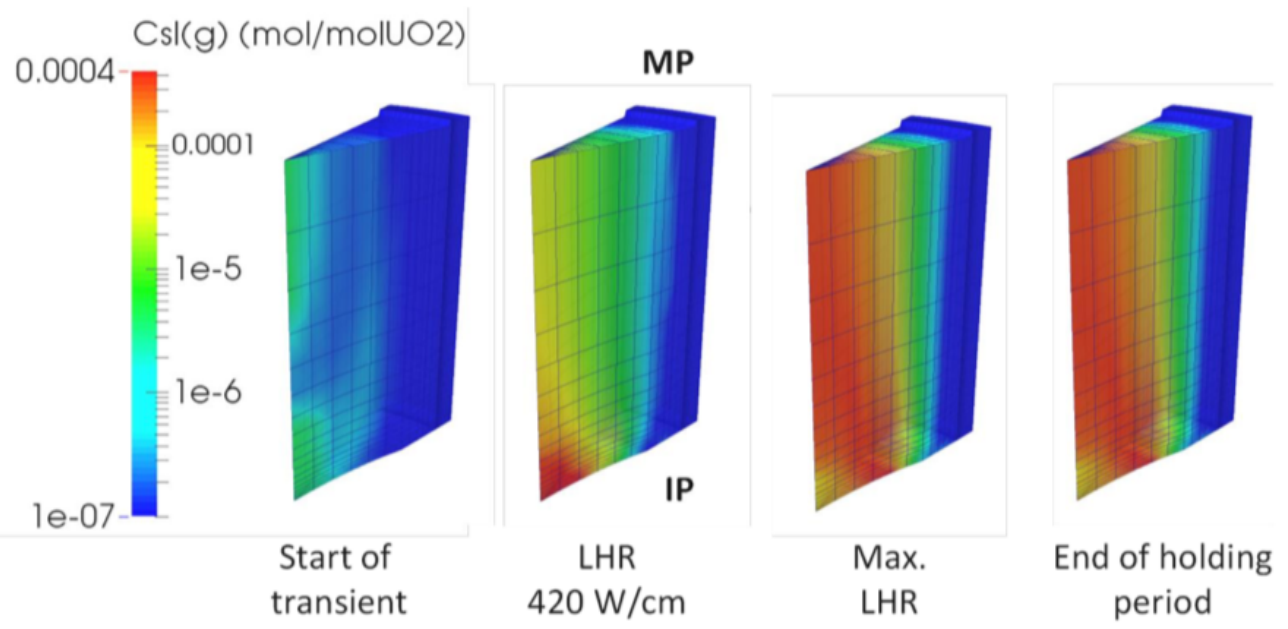

Figure 6. An example calculation with ALCYONE that predicts the concentration of CsI gas in urania fuel during a transient [14].

In addition to enhancing the predictive capabilities of ALCYONE through an improved handling of thermochemistry, Introïni et al. [62] also made progress in numerical coupling strategies to improve computational performance. One algorithm called the "spatial strategy" was developed to more efficiently solve the multi-physics problem by providing initial estimates of the stable phases by reorganizing mesh elements with respect to temperature and pressure [62]. Also, a second algorithm called the "hybrid strategy" was developed that combines the spatial strategy with one that initializes thermochemical calculations based on the previous time step [62].

A methodical set of numerical experiments were performed by Introïni et al. that benchmarked the computational expense associated with different implementations of OPENCALPHAD in ALCYONE. As is illustrated in Figure 7, there is a significant reduction in computational expense when the aforementioned numerical strategies are implemented, particularly the spatial strategy technique [62]. Moreover, a significant improvement in performance was realized when ALCYONE was coupled with OPENCALPHAD in comparison to when it is coupled with ANGE [62]. 


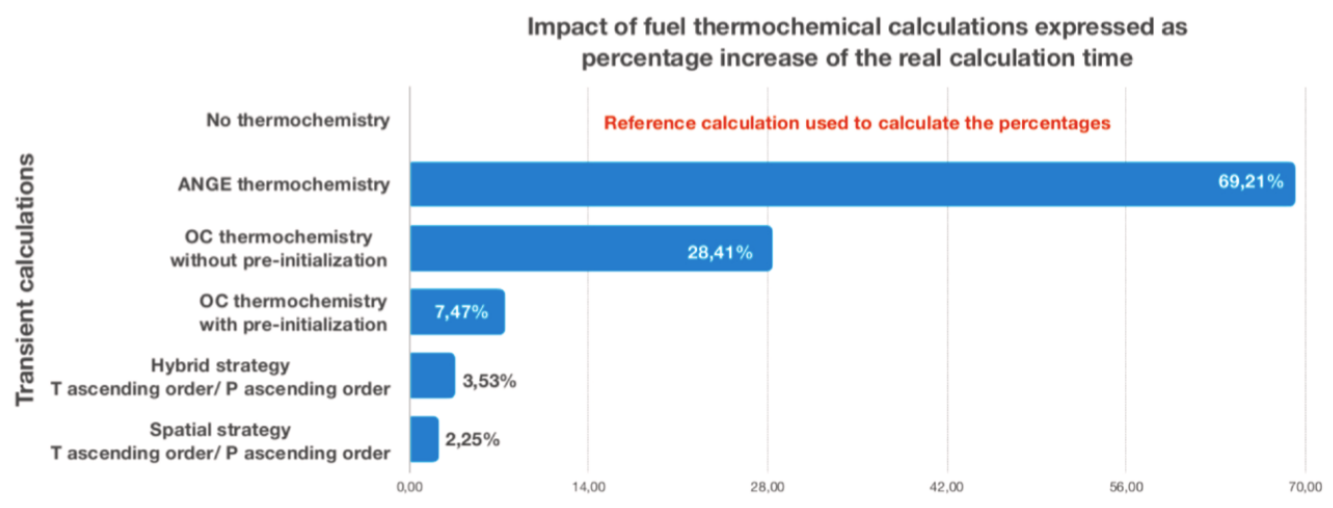

Figure 7. Reported computational performance benchmarking by Introïni et al. [62] on various programming strategies of coupling ALCYONE and OPENCALPHAD.

\subsection{GERMINAL}

GERMINAL [64] is a fuel performance code developed on the PLEIADES platform, which is intended to simulate MOX fuel behaviour in Sodium cooled Fast Reactors (SFR) under normal and abnormal conditions [14]. Since the fuel conditions are different in an SFR compared to a PWR, the phenomena of interest are somewhat different. GERMINAL is intended to simulate heat transfer, fuel restructuring, and the joint oxide cladding (aka, "Joint Oxyde Gaine" (JOG)). The latter phenomena is unique to MOX fueled SFRs, whereby the increased fuel temperatures contribute to volatile and semi-volatile fission products migrating to the stainless steel cladding followed by condensation, forming a new phase typically called 'JOG' [65]. This phase is primarily comprised of molybednum and cesium oxides, in addition to others, as reported by Samuelsson et al. [66]. The JOG layer affects heat transfer and may contribute to Fuel Cladding Chemical Interaction (FCCI), which increases the probability of fuel failure [12].

GERMINAL simulates the formation of JOG, including the thickness and its composition, which requires thermodynamic calculations as input. Two different GEM codes have been coupled with GERMINAL (i.e., ANGE and OPENCALPHAD) and two different databases have been used (i.e., TBASE and TAF-ID). ANGE has historically been used in GERMINAL, which is essentially a modified version of SOLGASMIX [59], and uses the TBASE thermodynamic database $[60,61]$. The motivation for replacing ANGE with OPENCALPHAD in recent developments of GERMINAL is to use improved representations of irradiated fuel using the TAF-ID database [66].

Samuelsson et al. report that 15 chemical elements in the TAF-ID were included in the GERMINAL-OPENCALPHAD coupling, whereby several chemical elements were grouped together based on some chemical similarities [66]. The motivation for grouping was twofold: (i) to reduce computational expense, and (ii) some chemical elements of interest in the fuel were not captured by the TAF-ID [66]. Some example surrogates that were considered by Samuelsson include grouping $\mathrm{Ba}$ and $\mathrm{Sr}$ (together to minimize costs), and $\mathrm{I}$ and $\mathrm{Br}$ (because $\mathrm{Br}$ is not in the TAF-ID) [66]. Overall, the use of OPENCALPHAD with the TAF-ID yielded improved predictions with respect to in-reactor experiments compared to predictions made with ANGE and TBASE [66].

\section{Class II: Industrial Nuclear Fuel Performance and Safety Codes}

This section reviews Class II nuclear fuel codes that are focused on accident conditions for industrial applications. As was the case in the previous section, the following review will focus on aspects specific to thermodynamic calculations informing Class II codes and will not discuss those codes in a broader context. For the interested reader, Kurata et al. give a comprehensive overview of fuel chemistry with respect to SA behaviour [67]. Early work from Cubicciotti is summarized in Section 3.1, the VICTORIA code is reviewed in Section 3.2, MFPR in Section 3.3, MELCOR in Section 3.4, ASTEC in Section 3.5, and SOURCE 
in Section 3.6. Fuel performance codes that are not informed by thermodynamics will not be discussed here as they are out of scope. For the interested reader, review articles are available on oxide fuel performance codes [68,69], metallic fuel performance codes [70], and TRISO fuel performance [71].

\subsection{Cubicciotti}

Cubicciotti pioneered much of the work in thermodynamically informed SA analyses at the Electric Power Research Institute (EPRI) [72,73]. Early work involved the development of a thermodynamic treatment of irradiated fuel with fission products with the objective of simulating fission product vaporization, particularly involving molten core-concrete interaction [72]. Thermodynamic calculations were performed with the SOLGASMIX software from Eriksson [59]. The analysis was handled in two stages, whereby the first stage simulated fission product transport within the fuel (which is the rate limiting step for the volatiles $\mathrm{Xe}, \mathrm{Kr}, \mathrm{Cs}$, and I), while the second stage simulated fission product vaporization (which is the rate limiting step for other fission products) [73]. The thermodynamic database consisted of the $\mathrm{UO}_{2}$ fluorite matrix and an ideal gas. Several fission products had limited solubility in the fluorite matrix; however, their treatment was assumed to be ideal [73].

\subsection{VICTORIA}

The VICTORIA code was developed with the intent of predicting fission product release during a severe accident in a similar fashion as Cubicciotti [72] but with greater focus on ex-core release applications [26]. VICTORIA used a thermodynamic database to capture irradiated fuel thermochemistry with fission products with a total of 26 chemical elements and 288 species [74].

A critical independent review of the thermochemistry analyses within VICTORIA was performed by Olander and Mubayi [74], which identified several strengths and areas of improvement. First, a key strength of the work that was identified by Olander was that VICTORIA considered the largest number of chemical elements in comparison to other SA codes. Some areas of improvement include the Gibbs energy equations of several pure species, the omission of some key fission products (e.g., Ce, Pr, Gd, La, Nd, Dy, Y, and some noble metals), the handling of $\mathrm{UO}_{2}$ non-stoichiometry, and the handling of condensed phases [74]. First, it is important to acknowledge that these issues were raised in the late 1990s-there may have been significant improvements since Olander's review but not documented in the open literature. Second, the value of an independent assessment of the thermodynamic representation of irradiated fuel in VICTORIA is clear as an opportunity for continuous improvement. While it may be possible that such peer-reviews have been performed for other codes and reported in proprietary reports, it is valuable to have their findings reported in the open literature to benefit the broader field.

\subsection{MFPR}

The Module for Fission Product Release (MFPR) code [23] was developed by the Nuclear Safety Institute of the Russian Academy of Science (IBRAE) in collaboration with the Institut de Radioprotection et de Sûreté Nucléaire (IRSN) to simulate $\mathrm{UO}_{2}$ fuel and fission product behaviour. Applications include simulating NOC, LOCA, and SA behaviour [75]. MFPR has been validated against a large number of integral tests, such as VERCORS [76] and PHEBUS [77]. In addition to sophisticated models to capture fission gas bubble evolution and other matters related to fuel behaviour, MFPR has a chemistry module that informs diffusion calculations. The thermodynamic database contains 15 fission products in addition to uranium and oxygen, and includes the following phases: $\mathrm{UO}_{2}$ with dissolved fission products, noble metal phase with $\mathrm{Mo}$ and $\mathrm{Ru}$, molybdates, zirconates, uranates, gas and some stoichiometric solid phases like CsI [75]. Limitations of the formation of these phases due to kinetics are assumed negligible [75]. 
According to Veschunov et al., the MFPR chemistry module assumes semi-ideal chemistry in terms of the fission products dissolved in the fluorite matrix. Furthermore, the chemical potential of dissolved oxygen is represented by the Lindemer-Besmann equation [28]. While this correlation reliably reproduces experimentally measured oxygen potentials of $\mathrm{UO}_{2+x}$, it only applies to fresh fuel. Oxygen potential profiles of irradiated fuel are quite different-not only in magnitude, but there are also multiple plateaus and changes in curvature as a result of phase transitions [31]. It is unclear whether the thermodynamic representation of irradiated fuel can reproduce experimentally derived phase diagrams, particularly when a semi-ideal approximation is used. Nevertheless, this approximation may be quite reasonable given that the overall objective is to simulate many phenomena related to fuel and fission product behaviour where other physical processes may have a greater impact.

\subsection{MELCOR}

MELCOR was developed by the Sandia National Laboratories (SNL) for the US Nuclear Regulatory Commission (NRC) to simulate SA progression of Light Water Reactors (LWR) [22]. It is an integral code that captures a number of stages of an accident, ranging from core degradation to fission product release from the plant. It is widely used with a large international userbase [22]. Several modules have been integrated into MELCOR, including VANESA [78]. The VANESA code, which was also developed by SNL for the US NRC, provides a mechanistic framework for predicting radionuclide release and aerosol generation in latter stages of a SA, such as corium-concrete interactions [78]. Thermodynamic and kinetic models are included to model changes to fuel chemistry with a particular focus on fission product vaporization, which is the dominant mechanism for fission product release [78].

The thermodynamic representation of irradiated fuel with fission products, control rods, concrete bearing materials, and a steam/hydrogen atmosphere is handled with a GEM routine. Unfortunately, little has been reported in the open literature on this routine. The primary output of these calculations is the vapour pressures of various fission product elements. The database includes 25 chemical elements, a series of Gibbs energy equations for the pure species, and activity coefficients of species to capture nonideal mixing [78]. The activity coefficients were derived from thermodynamic models based on Redlich Kister correlations [79], which are mainly compositional dependent while some are also temperature dependent [78]. The database captures a number of stoichiometric phases with fission product solubility in some solution phases; however, the thermodynamic description is incomplete or missing for a number of sub-systems (e.g., U-O, La-O, Ce-O) [78]. Some other known limitations include the handling of nonstoichiometry of $\mathrm{UO}_{2 \pm x}$ and miscibility gaps (e.g., $\mathrm{UO}_{2}-\mathrm{Al}_{2} \mathrm{O}_{3}$ ) [78].

\subsection{ASTEC}

ASTEC (Accident Source Term Evaluation Code) is an integral code co-developed by IRSN and the German Gesellschaft für Anlagen und Reaktorsicherheit mbH [17]. The primary objective of ASTEC is to simulate SA progression of LWRs, ranging from various initiating events to fission product release from containment [17]. Similar to MELCOR, models are used to capture various physical and chemical behaviours with a particular focus on fuel and fission product release. The ASTEC code has been validated with respect to a large experimental data suite, most notably the VERCORS program [76].

ASTEC contains several modules aimed at modelling various aspects of SA progression. The ELSA module within ASTEC simulates fission product release from defective fuel, which is informed by thermodynamic calculations including 42 chemical elements [80]. The handling of fission products are partitioned in three categories: volatiles, semi-volatiles, and low-volatiles [17].

Unlike the work of Cubicciotti [73] and MELCOR, a Gibbs energy minimizer is not directly coupled to ASTEC, but rather a series of equilibrium constants are used instead. An 
empirical correlation relating temperature and oxygen partial pressure is used to model fuel stoichiometry, $x$ in $\mathrm{UO}_{2 \pm x}$ [80]. A number of correlations are used to capture specific chemical reactions (e.g., $\mathrm{CeO}_{2(s)}=\mathrm{Ce}_{g}+\mathrm{O}_{2(g)}$ ), which are temperature dependent and sometimes include activity coefficients to account for non-ideal behaviour [81]. Based on the material published in the open literature, it appears that these models do not capture fission product solubility in the fluorite matrix, fuel melting, or vaporization. Therefore, the departure from stoichiometry, $x$, appears to assume fresh fuel and does not account for the effects of irradiation on the fuel matrix. A much larger number of chemical elements are considered here in comparison to other Class II codes.

\subsection{SOURCE}

SOURCE $[25,82,83]$ is an Industry Standard Toolset (IST) code used to perform source term analyses of CANDU (Canadian Deuterium Uranium) stations under abnormal conditions. Fission product transport is simulated within the fuel in a manner akin to most fuel performance codes (i.e., intergranular and intragranular diffusion) to predict the fission product inventory in the fuel-clad gap. While most fuel performance codes limit fission product transport to the gap, which is appropriate under NOC conditions, SOURCE includes models for fission product vaporization from the fuel surface following cladding failure [84]. This is handled in all production versions of SOURCE via a set of look-up tables that were derived from a series of thermodynamic calculations by Corse [85] and Lewis et al. [86]. Those lookup tables vary temperature, hydrostatic pressure, air to steam ratios, and fuel to gas ratios. That thermodynamic assessment was based on a database that included ideal gas, an ideal liquid solution, and several solid stoichiometric phases [85]. Therefore, it did not capture non-stoichiometry of the fluorite phase, fission or activation products dissolved in the fluorite phase, non-congruent melting, or secondary phases (e.g., noble metals).

The same research group that originally derived the aforementioned set of look-up tables executed a concerted research campaign to further improve upon the thermodynamic representation of irradiated fuel, including a treatment for non-stoichiometric $\mathrm{UO}_{2 \pm x}[27,31]$, noble metal phases [87], and some dissolved fission and activation products [88]. This revised database is the RMCTT [89]. This improved database was later used in a prototypic version of SOURCE by Barber [84] via direct coupling between SOURCE and the commercial thermodynamic software CHEMAPP [19]. As a result of this improved representation of nuclear fuel thermodynamics, the fractional fission gas release predicted by SOURCE was in closer agreement to experimental measurements [84] compared to the previous thermodynamic assessment from Corse [85]. While reassuring, this is not surprising given the great improvements in the thermodynamic treatment of the fuel. Another important finding from the work of Barber was that the direct coupling of CHEMAPP to SOURCE added an acceptable increase in computational expense that remained tractable [84].

While the thermodynamic representation of irradiated fuel significantly evolved from the work of Corse [85] to the RMCTT [89], there remained a number of gaps in the database. For instance, the solubility of fission and activation products in the fuel was not rigorously described (e.g., there was no assessment for the ternary U-Pu-O system) and several other minor phases were not captured. Recently, a further improved analysis of irradiated fuel was performed by Piro [90] for input to SOURCE, which was based on the TAF-ID [63]. The primary objective of this assessment was to predict the partial pressures of fission product elements as input to source term analyses in SOURCE. In addition to predicting equilibrium fission gas concentrations, the onset temperature to fuel volatilization was predicted under a variety of conditions [90].

\section{Discussion and Perspectives}

The previous sections reviewed experiences reported in the open literature involving various nuclear fuel codes that have been informed by thermodynamic calculations. Those sections were largely a literature review, which is obviously fact-based, while this 
section discusses those findings and offers some perspectives moving forward based on lessons learned by the community as a whole. As a disclaimer, this section involves some speculation and opinion on the author's part. The intent of this section is to offer some non-biased perspectives based on the foregoing literature review that may be helpful to the broader nuclear fuel modelling community in future endeavours when thermodynamic calculations come into play. To preserve some focus, this section is partitioned into the following subsections: applications (Section 4.1), thermodynamic databases (Section 4.2), thermodynamic calculations (Section 4.3), and quality assurance (Section 4.4).

\subsection{Applications}

Class I codes, which are based on research and development applications, have been largely focused on capability development, knowledge gap identification, the interpretation of experimental measurements, and guiding future experiments. Several new predictive capabilities have been reported in Section 2, including spatial and temporal changes to fuel chemistry under NOC, thermodynamically informed solid-state diffusion, input to phase field simulations, and contributions to multi-physics simulations of defective fuel oxidation.

Some cases in Section 2 also demonstrated how Class I codes can be used to support knowledge gap identification. For example, the AMP/ORIGEN-S/THERMOCHIMICA coupling (Section 2.2) raised some relevant questions on the potential role of the rim effect affecting oxygen transport towards the inner clad surface, which may potentially serve a beneficial role in mitigating PCI. Again, some of these hypotheses remain speculative at this time, but give impetus and guidance to perform separate effects tests to better understand their behaviours. Several cases in Section 2 have demonstrated value in interpreting experimental results. For example, Böhler et al. reported phase field simulations of MOX fuel that were helpful to interpret laser flash melting experiments, which resulted in changing the measurement procedures [32].

Some multi-physics approaches described in Section 2 may be useful in guiding future experimental campaigns. For example, multi-physics simulations of metallic fuel, as described in Section 2.3.2, may be helpful to explore alternate fuel designs to mitigate fuel clad chemical interaction [91]. Another potential application of multi-physics simulations informed by thermodynamic calculations is the behaviour of molten salts in a conceptual Molten Salt Reactor (MSR). Predicted phase transformations and chemical reactions under abnormal conditions may be helpful to identify knowledge gaps in MSRs. This may require the coupling of thermodynamics to a computational fluid dynamics code due to the liquid state of the fuel in an MSR.

An on-going point of discussion with phase field codes is the manner in which thermodynamic calculations are provided as input. The direct coupling of a GEM code to a phase field code provides the greatest level of fidelity; however, it may be cost prohibitive. Furthermore, it's unclear, at least at this time, whether the added simulation fidelity warrants the large additional computational expense. Some progress has been demonstrated by Schwen et al. [50] in automatic differentiation (Section 2.4); however, one could expect some pertinent issues if the thermodynamic models that are used yield under-determined equations. The use of look-up tables, as was done by Hirschorn et al. [45] (Section 2.3.2), appears to be a practical approach; however, the size of these tables may increase exponentially when moving towards larger multi-component systems, which may be problematic. Clearly, there are pros and cons to all of the aforementioned approaches. A concerted investigation to examine these points may be worth pursuing.

There have not been any reports of fuel performance codes intended for industrial use that support safety and licensing efforts that are informed by thermodynamic analyses. One example is the TRANSURANUS code [92], which is used to support various industrial and regulatory matters, particularly in Europe. TRANSURANUS is used to simulate many aspects of LWR fuel performance, but it does not have a need to be informed by any thermodynamic calculations. Furthermore, there is a concern about the total compute 
time, whereby industrial fuel performance codes need to run rapidly and on a typical workstation. Having to wait hours or even days on a workstation or requiring the use high performance computing systems is not practical for industrial applications. Direct coupling with thermodynamic codes increases computational expense and is a valid concern in this context.

ALCYONE and GERMINAL, which are both considered here as Class I codes, have been used on occasion for industrial applications and are both informed by thermodynamic calculations. The primary application of thermodynamics in ALCYONE is to inform predictions of PCI failure, specifically the availability of volatile iodine in contact with Zr-bearing cladding. GERMINAL is principally aimed at simulating MOX fuel in a SFR, whereby thermodynamic calculations are mainly used to predict the formation of the JOG. The value of thermodynamic coupling in a fuel performance code is perhaps most evident with the case of GERMINAL in predicting the behaviour of JOG.

Overall, the value of informing industrial nuclear fuel performance codes by thermodynamic models is less clear than with research-based nuclear fuel codes (i.e., Class I) or accident-based Class II codes. This may change if non-conventional reactors are commercialized in the coming years (e.g., metallic fuels for SFR or fluoride/chloride salts for MSRs) where different phenomena may be experienced.

The manner in which thermodynamic calculations inform Class II codes varies, including look-up tables, empirical correlations, and direct coupling with a thermodynamic solver. The primary benefit of using look-up tables and empirical correlations is to reduce computational expense; however, one would not benefit from the same simulation fidelity as direct coupling with a thermodynamics code. The main disadvantage of direct coupling with a thermodynamics code is the increase in computational expense. These pros and cons are similar to what was discussed earlier with Finite Element Analysis (FEA) based codes, notwithstanding the issue of computational expense is much greater with FEA codes compared to SA codes due to the much greater number of executions required. For example, Barber reported that the additional computation expense with coupling CHEMAPP with SOURCE was quite acceptable [84].

\subsection{Thermodynamic Databases}

Many reports of Class II codes have involved about 20-25 chemical elements in the thermodynamic database to represent irradiated $\mathrm{UO}_{2}$ fuel. This consistent number may be a coincidence, it may be a good representation of irradiated fuel, or it may be due to software constraints of legacy codes. Regardless of the reason, there has been great progress in thermodynamic representation of irradiated fuel over the past decade and it is worth questioning whether a larger number of chemical elements and phases should be included in thermodynamic analyses in Class II codes. An exception has been ASTEC, which uses more than 40 elements. Clearly, this is dependent on the level of comprehensiveness of the database.

Several previous analyses have grouped some chemical elements together as chemical analogues, perhaps most notably by Kleykamp [93]. While this practice seems reasonable for some circumstances, it is noteworthy that chemical analogues have their limitations. For example, several of the noble metals are often grouped together, such as Mo and Tc. While they behave similarly in a condensed state when only involving the metals or in oxide fuel, their behaviour in aqueous conditions are markedly different [31].

While the ideal approach is to treat each chemical element individually to avoid making any assumptions, it may not always be practical due to the increase in computational expense and/or due to lack of data for a particular system, whereby an analogue is used as an approximation. It may be prudent to make a careful assessment prior to any chemical analogues are considered while explicitly acknowledging the assumption(s) made. Furthermore, it is unclear how much of an impact simplifying a thermodynamic treatment-by reducing the number of chemical elements, using a simpler thermodynamic 
model, or using look-up tables-may have on the final results of any analysis. Obviously, this is very much application specific and would require a careful assessment.

Thermodynamic databases of nuclear fuels have evolved significantly since the 1980s, whereby some early investigations treated the irradiated fuel as stoichiometric with several stoichiometric secondary phases and an ideal gas, to comprehensive databases that contain hundreds of fully assessed binary and ternary systems that are based on sophisticated thermodynamic models with multiple sublattices. Furthermore, more recent database development efforts are informed by a greater number of experimental data that cover a larger parameter space due to advances in experimental techniques. Given that thermodynamic models are empirical, the quality of the model and its corresponding database is ultimately limited by the quality of the experimental data used to generate it. Perhaps the greatest challenge in experimental measurements related to nuclear fuel is when dealing with vaporization at high temperatures, which is more relevant in the context of fuel safety. Furthermore, measurements of irradiated fuels have the added challenge of requiring experiments to be performed in a hot cell facility. Typically, isotopically benign surrogates are used in-laboratory that are chemically equivalent but isotopically stable to avoid the need to perform experiments in a hot cell. For example, one could use Cs-133 (stable) instead of Cs-137 (not stable)-the same chemical element is used but the former is radioactively stable and can more easily be handled in a laboratory.

Ongoing efforts over many years have focused on thermodynamic database advancement together with several experimental campaigns to inform model development using the CALPHAD method [1]. Two databases that have experienced significant attention are TAF-ID [63] and MEPHISTA [94]. While there remains some knowledge gaps in the thermodynamic assessment of irradiated $\mathrm{UO}_{2}$ fuel, including contact with other components like concrete, one may argue that the community may be reaching a point of diminishing returns. One could argue that the thermodynamic representation of $\mathrm{UO}_{2}$ fuel in a particular database is sufficient for a particular application, while other factors (e.g., aerosolization) may not be as well understood and may require greater attention. This obviously remains application specific.

The thermodynamic representations of other fuel designs-such as $\mathrm{UCO}, \mathrm{UCN}, \mathrm{UZr}$, and particularly molten fluoride and chloride salts-are not nearly as mature as $\mathrm{UO}_{2}$ fuel and a much larger number of knowledge gaps remain. Some knowledge gap assessments have already been made to help provide steerage to future experimental and modelling efforts (e.g., McMurray et al. [95]). This will likely be an ongoing activity in the coming years. International collaboration involving multi-faceted experimental campaigns, the development of models using state-of-the-art computational techniques, and a quality control program is an effective approach to reach this goal.

A common trend observed in this review was that the description of any thermodynamic database for any application was often kept to a minimum and lacked sufficient detail for a reader to assess its fidelity and limitations. For example, it was unclear whether some thermodynamic treatments could even reproduce experimentally derived phase diagrams, or if pertinent binary systems in a database were assessed at all. It would be prudent for future efforts to document the capabilities and limitations of any particular database, including detailed experimental validation efforts.

\subsection{Thermodynamic Calculations}

Several different approaches for thermodynamic calculations to inform fuel codes have been reported in the literature, including look-up tables, empirical correlations, and direct coupling with a thermodynamics code. All three of these approaches have both pros and cons. For instance, the use of look-up tables is perhaps the most computationally expedient, resulting in faster run-times, but lacks the level of fidelity and versatility of direct coupling with a thermodynamics code. Ultimately, one can question whether the increased level of fidelity warrants the increase in computational expense or if it is even necessary to do so at all. 
The main limitation in using look-up tables or empirical correlations is the limited level of fidelity of the simulation, which is limited to a particular window of application. For example, a look-up table may involve a large number of system parameters, which may yield tables that are colossal in size-perhaps prohibitively large to completely capture the entire set of parameters. Furthermore, there may be a number of details that cannot be easily captured (or at all) by such look-up tables or correlations (e.g., fission product speciation or phase transformations). On the other hand, a great advantage of the use of look-up tables and correlations is the low computational requirements and also the low probability for calculation errors/failure in a thermodynamics code (e.g., convergence).

A common challenge experienced with coupling a nuclear fuel code with a thermodynamics code is the increase in computational expense, particularly when solved on a FEA mesh. This issue has not been reported in the open literature among Class II SA codes; in fact, Barber reported that the increased computational expense with coupling ChemApp with SOURCE was quite acceptable [84]. The reason why the computational increase with code coupling is more problematic with FEA codes is simply because of the very large number of thermodynamic calls associated with a large number of finite elements in space and steps in time.

This increase may be due to the specific software that is used, the database used by that software, the manner in which the database is used, and/or the manner in which the software is implemented in a fuel code. Typically, the user may not have much control on any of these factors with exception of perhaps how the database is used. While it may seem trivial, removing unnecessary species, phases, and elements can significantly reduce computational expense. Software developers, on the other hand, obviously have much more control on the other foregoing factors. One can implement various algorithms to more efficiently solve thermodynamic equilibria (e.g., performance enhancing algorithms by Piro and Simunovic [96]) or improve the manner in which a Gibbs energy minimizer is coupled to a fuel code. A noteworthy observation is that little attention has been devoted to parallelizing thermodynamics codes while much greater attention has been focused on how a thermodynamics code is used in a larger fuel code. Since each individual calculation is rather inexpensive but needs to be called numerous times within a single timestep, it makes sense to run many serial instances in parallel whereby each individual instance is executed efficiently according to Amdahl's law. Great progress has been reported by both Introïni et al. [62] and Poschmann et al. [41] in terms of strategies to efficiently couple such codes on a finite element mesh. Another aspect of thermodynamic codes that may have a large impact on computational performance and reliability is the global optimization algorithm that is used [97]. To date, there has been little reported in the literature to rigorously assess the performance and reliability of global optimization algorithms that have been used. This may be an area of future examination.

Another concept that may be worth exploring is a simplified approach to coupling thermodynamic codes to FEA codes. One experience that could be leveraged is how intragranular fission gas diffusion is often handled in fuel performance codes. Instead of modelling every grain in a fuel performance code, a few representative grains are selected across the radius and diffusion rates are interpolated across the fuel pellet. Perhaps a similar approach may be worth exploring in coupling equilibrium thermodynamics with an FEA code whereby thermodynamic calculations are not performed at every node on a mesh but instead on only a few nodes and thermodynamic values are then interpolated. One could anticipate challenges when phase transformations take place, which may result in large discontinuities and necessitate careful attention.

\subsection{Quality Assurance}

Verification, validation, and Software Quality Assurance (SQA) are important to nuclear fuel analyses, whereby the rigour of QA is typically determined by the intended use. For example, the QA requirements of an analysis informing safety and licensing is much higher than an analysis performed purely for research purposes. Here, verification refers to 
the numerical correctness and completeness of any model (Section 4.4.1), validation refers to how well a model and its use within a large code aligns with experimental measurements (Section 4.4.2), and SQA refers to the QA of a particular software (Section 4.4.3). The focus of this section will focus on QA specific to thermodynamic coupling with nuclear fuel codes.

\subsubsection{Verification}

If thermodynamic calculations are to inform nuclear reactor safety analyses, where a high degree of rigour is required, it may be worthwhile to have independent assessments of the thermodynamic database that is used to quantify coverage in parameter space and identify knowledge gaps. Given the tremendous complexity of the system, there are opportunities for unintentional errors and omissions, whereby an independent assessment can be quite helpful in identifying them. For example, the US NRC established a peer review committee to review VICTORIA, including thermochemical representations of irradiated fuel by Olander [74]. Perhaps the same could be done to other thermodynamic databases of various fuel forms, including UCO, UCN, molten salts, etc.

\subsubsection{Validation}

One can partition validation efforts into separate effects tests to validate a model and integral tests to validate a simulation or code. As far as validating thermodynamic models, which represent a specific phase, it is worth reiterating that thermodynamic models are empirical. That is to say that they are derived via non-linear regression based on a set of experimental data as input. Therefore, a specific model is inherently validated with respect to the conditions in which it was developed; however, the assemblage of models into a system often requires some interpolation and extrapolation outside that perimeter of experimental input, particularly for large multi-component systems. In terms of integral tests to validate a simulation or code, which may include fuel irradiations in a test reactor or data collected from the Fukushima accident, it becomes more difficult to differentiate the source of any errors. However, these tests give confidence to the overall analysis and some sense of uncertainties, which is obviously invaluable.

One important assumption with GEM calculations is that the conditions computed are at thermodynamic equilibrium and that kinetics is not directly captured. This assumption may be reasonable in some circumstances, such as several SA Class II codes whereby thermodynamic calculations typically apply to situations at very high temperatures and chemically reactive atmospheres. Furthermore, there are other assumptions and approximations in the overall analysis of a SA scenario that may be more impactful than thermodynamics. Yet this assumption may not always be valid where various kinetic phenomena may become important, particularly at low to modest temperatures. For example, several thermodynamic analyses of irradiated $\mathrm{UO}_{2}$ fuel under $\mathrm{NOC}$ predict the formation of a number of minor secondary phases notwithstanding post irradiation examinations typically only identifying 3-4 phases under NOC (i.e., fluorite, gas, and HCP noble metals-sometimes perovskites as well). Integral tests can be quite helpful in assessing the appropriateness of assuming thermodynamic equilibrium.

\subsubsection{Software Quality Assurance}

Documentation summarizing the QA of various nuclear fuel codes have been reported in the literature; however, the author has not found any reports in the open literature discussing SQA of thermodynamic codes-either commercial or open-source. It is possible that such SQA documents are proprietary and therefore not available in the open literature; however, the author has not found a detailed reporting of user requirements, software design, unit testing, application testing, convergence coverage, or formal independent peer-reviews of the source code [98]. A limited discussion on the necessary [99] and sufficient [97] requirements for convergence as it relates to numerical verification has been reported, but nothing comprehensive. If thermodynamic equilibrium software are to be used to support nuclear safety analyses, this may be an area that may require further 
attention and discussion in the open literature. Two particular topics that would be worth exploring are: (i) ensuring numerical convergence in a convincing manner over a very wide range of parameter space and databases, and (ii) ensuring any system is at a global minimum rather than a local minima.

\section{Conclusions}

A review has been provided of two classes of nuclear fuel codes that have been informed by thermodynamic calculations (Class I: research and development codes, and Class II: industrial fuel performance and safety codes). The following conclusions have been made from this review:

1. Class I codes have demonstrated some useful progress in thermodynamically informed nuclear fuel codes, such as helping interpret experimental findings, capability development, and knowledge gap identification.

2. Class II codes have demonstrated a widespread utility of thermodynamically informed calculations under SA conditions whereby the added value is mainly in predicting the release of low-volatile fission products and fuel volatilization.

3. There have not been any reports of Class II codes being informed by thermodynamic calculations under NOC conditions. The value in doing so is not as clear, which is mainly because of differences in intended applications.

4. Thermodynamic databases of irradiated $\mathrm{UO}_{2}$ and $(\mathrm{U}, \mathrm{Pu}) \mathrm{O}_{2}(\mathrm{MOX})$ fuel have significantly evolved and benefited from a plethora of experimental data. International co-operation has proven effective in database development.

5. Thermodynamic databases of irradiated non-conventional fuels (e.g., U-C-O, U-C-N, molten salts) are not as well developed and require further investigations.

6. Significant improvements in simulation fidelity have been reported with direct coupling of nuclear fuel codes with a thermodynamic code, such as fission product solubility, fuel oxidation, etc. Yet the added simulation fidelity of code coupling may not always be warranted given the potential for a large increase in computational expense. The increase in computational expense can be large for FEA codes but modest for integral system level codes.

7. There have not been any concerted discussions or reports in the open literature related to SQA of thermodynamic equilibrium codes. While this may be acceptable for use with Class I codes at this time, this is an area that may require careful attention for Class II codes moving forward.

Funding: This research was undertaken, in part, thanks to funding from the Canada Research Chairs program (950-231328) and Discovery Grants program of the Natural Sciences and Engineering Research Council of Canada.

Institutional Review Board Statement: Not applicable.

Informed Consent Statement: Not applicable.

Data Availability Statement: Not applicable.

Acknowledgments: The author expresses his appreciation to M. Welland (CNL), M.R. Tonks (UF), F. Gelbard (SNL), J. Sercombe (CEA), P. Van Uffelen (JRC), and F. Kremer (IRSN) for helpful technical discussions.

Conflicts of Interest: The author declares no conflict of interest.

\section{References}

1. Kaufman, L.; Bernstein, H. Computer Calculation of Phase Diagrams with Special Reference to Refractory Metals; Academic Press: Cambridge, MA, USA, 1970.

2. White, W.; Johnson, S.; Dantzig, G. Chemical Equilibrium in Complex Mixtures. J. Chem. Phys. 1958, 28, 751-755. [CrossRef]

3. Bale, C.; Bélisle, E.; Chartrand, P.; Decterov, S.; Eriksson, G.; Gheribi, A.; Hack, K.; Jung, I.H.; Kang, Y.B.; Melançon, J.; et al. FactSage Thermochemical Software and Databases, 2010-2016. Calphad 2016, 54, 35-53. [CrossRef] 
4. Sundman, B.; Jansson, B.; Andersson, J.O. The Thermo-Calc Databank System. Calphad 1985, 9, 153-190. [CrossRef]

5. Otis, R.; Liu, Z.K. pycalphad: CALPHAD-based computational thermodynamics in python. Open Res. Softw. 2017, 5. [CrossRef]

6. Sundman, B.; Lu, X.G.; Ohtani, H. The implementation of an algorithm to calculate thermodynamic equilibria for multi-component systems with non-ideal phases in a free software. Comput. Mater. Sci. 2015, 101, 127-137. [CrossRef]

7. Piro, M.; Simunovic, S.; Besmann, T.; Lewis, B.; Thompson, W. The Thermochemistry Library THERMOCHIMICA. Comput. Mater. Sci. 2013, 67, 266-272. [CrossRef]

8. Lukas, H.; Fries, S.; Sundman, B. Computational Thermodynamics: The Calphad Method; Cambridge University Press: Cambridge, UK, 2007.

9. Hillert, M. Phase Equilibria, Phase Diagrams and Phase Transformations-Their Thermodynamic Basis, 2nd ed.; Cambridge University Press: Cambridge, UK, 2012.

10. Liu, Z.K.; Wang, Y. Computational Thermodynamics of Materials; Cambridge University Press: Cambridge, UK, 2016.

11. Pelton, A. Phase Diagrams and Thermodynamic Modeling of Solutions; Elsevier: Amsterdam, The Netherlands, 2018.

12. Guéneau, C.; Dumas, J.; Piro, M. In-reactor behavior. In Advances in Nuclear Fuel Chemistry; Piro, M., Ed.; Elsevier: Amsterdam, The Netherlands, 2020; Chapter 11, pp. 419-467.

13. Guéneau, C.; Asta, M.; Sundman, B. Computational thermodynamics: Application to Nuclear Materials. In Comprehensive Nuclear Materials, 2nd ed.; Konings, R., Stoller, R., Eds.; Elsevier: Amsterdam, The Netherlands, 2020; Volume 1, Chapter 26, pp. 814-849.

14. Michel, B.; Ramìere, I.; Viallard, I.; Introini, C.; Lainet, M.; Chauvin, N.; Marelle, V.; Boulore, A.; Helfer, T.; Masson, R.; et al. Chapter 9-Two fuel performance codes of the PLEIADES platform: ALCYONE and GERMINAL. In Nuclear Power Plant Design and Analaysis Codes; Wang, J., Li, X., Allison, C., Hohorst, J., Eds.; Woodhead: Sawston, UK, 2021.

15. Clarno, K.; Philip, B.; Cochran, W.; Sampath, R.; Allu, S.; Barai, P.; Simunovic, S.; Berrill, M.; Ott, L.; Pannala, S.; et al. The AMP (Advanced Multi-Physics) Nuclear Fuel Performance code. Nucl. Eng. Des. 2012, 252, 108-120. [CrossRef]

16. Baurens, B.; Sercombe, J.; Riglet-Martial, C.; Desgranges, L.; Trotignon, L.; Maugis, P. 3D thermo-chemical-mechanical simulation of power ramps with ALCYONE fuel code. J. Nucl. Mater. 2014, 452, 578-594. [CrossRef]

17. Cantrel, L.; Cousin, F.; Chevalier-Jabet, L.; Marchetto, C. ASTEC V2 severe accident integral code: Fission product modelling and validation. Nucl. Eng. Des. 2014, 272, 195-206. [CrossRef]

18. Williamson, R.; Hales, J.; Novascone, S.; Tonks, M.; Gaston, D.; Permann, C.; Andrs, D.; Martineau, R. Multidimensional multiphysics simulation of nuclear fuel behavior. J. Nucl. Mater. 2012, 423, 149-163. [CrossRef]

19. Eriksson, G.; Königsberger, E. FactSage and ChemApp: Two tools for the prediction of multiphase chemical equilibria in solutions. Pure Appl. Chem. 2008, 80, 1293-1302. [CrossRef]

20. COMSOL Multiphysics Reference Manual; Technical Report CM020005; COMSOL; COMSOL Inc.: Stockholm, Sweden, 2019.

21. Tonks, M.; Gaston, D.; Millett, P.; Andrs, D.; Talbot, P. An object-oriented finite element framework for multiphysics phase field simulations. J. Nucl. Mater. 2012, 51, 20-29. [CrossRef]

22. Humpries, L.; Gauntt, R. MELCOR 2.2 severe accident analysis code-current status and plans for future. In IAEA Technical Meeting on the Status and Evaluation of Severe Accident Simulation Codes for Water Cooled Reactors; International Atomic Energy Agency: Vienna, Austria, 2017.

23. Veshchunov, M.; Ozrin, V.; Shestak, V.; Tarasov, V.; Dubourg, R.; Nicaise, G. Development of the Mechanistic code MFPR for Modelling Fisison-Product Release from Irradiated $\mathrm{UO}_{2}$ Fuel. Nucl. Eng. Des. 2006, 236, 179-200. [CrossRef]

24. Eriksson, G.; Rosen, E. General equations for the calculation of equilibria in multiphase systems. Chem. Scr. 1973, 4, 193-194.

25. Barber, D.; Iglesias, F.; Hoang, Y.; Dickson, L.; Dickson, R.; Richards, M.; Gibb, R. SOURCE IST 2.0: Development and beta testing. In Proceedings of the CANDU Fuel Conference, Niagara Falls, ON, Canada, 26-30 September 1999.

26. Heames, T.; Williams, D.; Bixler, N.; Grimley, A.; Wheatley, C.; Johns, N.; Domagala, P.; Dickson, L.; Alexander, C.; Osborn-Lee, I.; et al. VICTORIA: A Mechanistic Model of Radionuclide Behavior in the Reactor Coolant System under Severe Accident Conditions; Technical Report SAND90-0756; Sandia National Laboratories: Albuquerque, NM, USA, 1992.

27. Higgs, J.; Lewis, B.; Thompson, W.; He, Z. A Conceptual Model for the Fuel Oxidation of Defective Fuel. J. Nucl. Mater. 2007, 366, 99-128. [CrossRef]

28. Lindemer, T.; Besmann, T. Chemical Thermodynamic Representation of $\mathrm{UO}_{2 \pm x}$. J. Nucl. Mater. 1985, 130, 473-488. [CrossRef]

29. Welland, M.; Thompson, W.; Lewis, B.; Manara, D. Computer Simulations of Non-Congruent Melting of Hyperstoichiometric Uranium Dioxide. J. Nucl. Mater. 2009, 385, 358-363. [CrossRef]

30. Manara, D.; Ronchi, C.; Sheindlin, M.; Konings, R. On the present state of investigation of thermodynamic properties of solid and liquid $\mathrm{UO}_{2+x}$. J. Nucl. Mater. 2007, 362, 14-18. [CrossRef]

31. Piro, M. Computation of Thermodynamic Equilibria Pertinent to Nuclear Materials in Multi-Physics Codes. Ph.D. Thesis, Royal Military College of Canada, Kingston, ON, Canada, 2011.

32. Böhler, R.; Welland, M.; Prieur, D.; Cakir, P.; Vitova, T.; Pruessmann, T.; Pidchenko, I.; Hennig, C.; Guéneau, C.; Konings, R.; et al. Recent advances in the study of the $\mathrm{UO}_{2}-\mathrm{PuO}_{2}$ phase diagram at high temperatures. J. Nucl. Mater. 2014, 448, 330-339. [CrossRef]

33. Manara, D.; Seibert, A.; Gouder, T.; Beneš, O.; Martel, L.; Colle, J.Y.; Griveau, J.C.; Walter, O.; Cambriani, A.; Blanco, O.; et al. Experimental Methods. In Advances in Nuclear Fuel Chemistry; Piro, M., Ed.; Elsevier: Amsterdam, The Netherlands, 2020; Chapter 2, pp. 89-158. 
34. Gauld, I.; Hermann, O.; Westfall, R. ORIGEN Scale System Module to Calculate Fuel Depletion, Actinide Transmutation, Fission Product Buildup and Decay, and Associated Radiation Terms; Technical Report ORNL/TM-2005/39, Version 6; Oak Ridge National Laboratory: Oak Ridge, TN, USA, 2005; Volume II, Section F7.

35. Piro, M.; Banfield, J.; Clarno, K.; Simunovic, S.; Besmann, T.; Lewis, B.; Thompson, W. Coupled thermochemical, isotopic evolution and heat transfer simulations in highly irradiated $\mathrm{UO}_{2}$ nuclear fuel. J. Nucl. Mater. 2013, 441, 240-251. [CrossRef]

36. Wieselquist, W.; Lefebvre, R.; Jessee, M. SCALE Code System, Version 6.2.4; Technical Report ORNL/TM-2005/39; Oak Ridge National Laboratory: Oak Ridge, TN, USA, 2020.

37. Lewis, B.; Thompson, W.; Iglesias, F. Fission Product Chemistry in Oxide Fuels. In Comprehensive Nuclear Materials; Konings, R., Ed.; Elsevier: Amsterdam, The Netherlands, 2012; Volume 2.20, pp. 515-546.

38. Piro, M.; Sunderland, D.; Livingstone, S.; Sercombe, J.; Revie, R.; Quastel, A.; Terrani, K.; Judge, C. Pellet-clad interaction behavior in zirconium alloy fuel cladding. In Comprehensive Nuclear Materials, 2nd ed.; Konings, R., Stoller, R., Eds.; Elsevier: Amsterdam, The Netherlands, 2020; Chapter 2.09, pp. 248-306.

39. Gaston, D.; Newman, C.; Hansen, G.; Lebrun-Grandié, D. MOOSE: A parallel computational framework for coupled systems of nonlinear equations. Nucl. Eng. Des. 2009, 239, 1768-1778. [CrossRef]

40. Simunovic, S.; Besmann, T.; Moore, E.; Poschmann, M.; Piro, M.; Clarno, K.; McMurray, J.; Wieselquist, W. Modeling and simulation of oxygen transport in high burnup LWR fuel. J. Nucl. Mater. 2020, 538, 152194. [CrossRef]

41. Poschmann, M.; Piro, M.; Simunovic, S. Acceleration of Thermochimica Calculations in BISON; Technical Report ORNL/TM2020/1473; Oak Ridge National Laboratory: Oak Ridge, TN, USA, 2020.

42. Poschmann, M.; Bajpai, P.; Fitzpatrick, B.; Piro, M. Recent developments for molten salt systems in Thermochimica. Calphad 2021, 75, 102341. [CrossRef]

43. Poschmann, M.; Piro, M.; Besmann, T.; Simunovic, S. Thermochemically-informed mass transport model for interdiffusion of U and $\mathrm{Zr}$ in irradiated U-Pu-Zr fuel with fission products. J. Nucl. Mater. 2021, 554, 153089. [CrossRef]

44. Kim, Y.; Hofman, G.; Hayes, S.; Sohn, Y. Constituent redistribution in U-Pu-Zr fuel during irradiation. J. Nucl. Mater. 2004, 327, 27-36. [CrossRef]

45. Hirschhorn, J.; Tonks, M.; Matthews, C. A CALPHAD-informed approach to modeling constituent redistribution in Zr-based metallic fuels using BISON. J. Nucl. Mater. 2021, 544, 152657. [CrossRef]

46. Bai, X.M.; Tonks, M.; Zhang, Y.; Hales, J. Multiscale modeling of thermal conductivity of high burnup structures in $\mathrm{UO}_{2}$ fuels. $J$. Nucl. Mater. 2016, 470, 208-215. [CrossRef]

47. Aagesen, L.; Andersson, D.; Beeler, B.; Cooper, M.; Gamble, K.; Miao, Y.; Pastore, G.; Tonks, M. Phase-field simulations of intergranular fission gas bubble behavior in $\mathrm{U}_{3} \mathrm{Si}_{2}$ nuclear fuel. J. Nucl. Mater. 2020, 541, 152415. [CrossRef]

48. Tonks, M.; Cheniour, A.; Aagesen, L. How to apply the phase field method to model radiation damage. Comput. Mater. Sci. 2018, 147, 353-362. [CrossRef]

49. Tonks, M.; Andersson, D.; Phillpot, S.; Zhang, Y.; Williamson, R.; Stanek, C.; Uberuaga, B.; Hayes, S. Mechanistic materials modeling for nuclear fuel performance. Ann. Nucl. Energy 2017, 105, 11-24. [CrossRef]

50. Schwen, D.; Aagesen, L.; Peterson, J.; Tonks, M. Rapid multiphase-field model development using a modular free energy based approach with automatic differentiation in MOOSE/MARMOT. Comput. Mater. Sci. 2017, 132, 36-45. [CrossRef]

51. Guéneau, C.; Dupin, N.; Sundman, B.; Martial, C.; Dumas, J.C.; Gossé, S.; Chatain, S.; Bruycker, F.D.; Manara, D.; Konings, R.J. Thermodynamic modelling of advanced oxide and carbide nuclear fuels: Description of the U-Pu-O-C systems. J. Nucl. Mater. 2011, 419, 145-167. [CrossRef]

52. Bajpai, P.; Poschmann, M.; Andrs, D.; Bhave, C.; Tonks, M.; Piro, M. Development of a new thermochemistry solver for multiphysics simulations of nuclear materials. In TMS 2020 149th Annual Meeting \& Exhibition Supplemental Proceedings; Springer: Berlin/Heidelberg, Germany, 2020; pp. 1013-1025.

53. Michel, B.; Sercombe, J.; Nonon, C.; Fandeur, O. Modeling of pellet cladding interaction. In Comprehensive Nuclear Materials; Konings, R., Ed.; Elsevier: Amsterdam, The Netherlands, 2012; Volume 3, pp. 677-712.

54. Marelle, V.; Goldbronn, P.; Bernaud, S.; Castelier, E.; Julien, J.; Nkonga, K.; Noirot, L.; Ramiere, I. New developments in ALCYONE 2.0 fuel performance code. In Proceedings of the Top Fuel 2016-Light Water Reactor (LWR) Fuel Performance Meeting, Boise, ID, USA, 11-15 September 2016.

55. Lemoine, F.; Bernard, D.; Federici, E. Validation assessment of neutron calculations for radial and azimuthal distributions of actinides and fission products in PWR rods. In Proceedings of the Water Reactor Fuel Performance Meeting, Chengdu, China, 11-14 September 2011.

56. Noirot, L. MARGARET: A comprehensive code for the description of fission gas behavior. Nucl. Eng. Des. 2011, 241, 2099-2118. [CrossRef]

57. Baron, D.; Thevenin, P.; Largenton, R.; Masson, R.; Pujet, S.; Arnaud, R. CYRANO3 an EDF nuclear fuel performance code designed for engineering applications. In Proceedings of the 10th International Conference on CANDU Fuel, Toronto, ON, Canada, 5-8 October 2008.

58. GALILEO Fuel Rod Thermal-Mechanical Methodology for Pressurized Water Reactors; Rev1 ANP-10323NP; Framatome: La Défense, Courbevoie, France, 2018.

59. Eriksson, G. Thermodynamic studies of high temperature equilibria: XII. SOLGASMIX, A computer program for calculation of equilibrium compositions in multiphase systems. Chem. Scr. 1975, 8, 100-103. 
60. Cordfunke, E.; Konings, R. Thermochemical data for reactor materials and fission products: The ECN database. J. Phase Equilibria 1993, 14, 457-464. [CrossRef]

61. Schram, R.; Konings, R.; Rijnsburger, W. TBASE CONSULT Manual; Technical Report; The Netherlands Energy Research Foundation: Petten, The Netherlands, 2002.

62. Intrö̈ni, C.; Sercombe, J.; Sundman, B. Development of a robust, accurate and efficient coupling between PLEIADES/ALCYONE 2.1 fuel performance code and the OpenCalphad thermo-chemical solver. Nucl. Eng. Des. 2020, 369, 110818. [CrossRef]

63. Guéneau, C.; Dupin, N.; Kjellqist, L.; Geiger, E.; Kurata, M.; Gossé, S.; Corcoran, E.; Quaini, A.; Hania, R.; Smith, A.; et al. TAF-ID: An international thermodynamic database for nuclear fuels and applications. Calphad 2021, 72, 102212. [CrossRef]

64. Lainet, M. GERMINAL, a fuel performance code of the PLEIADES platform to simulate the in-pile behavior of mixed oxide fuel pins for sodium-cooled fast reacors. J. Nucl. Mater. 2019, 516, 30-53. [CrossRef]

65. Guérin, Y. Fuel performance of fast spectrum oxide fuel. In Comprehensive Nuclear Materials; Konings, R., Ed.; Elsevier: Amsterdam, The Netherlands, 2012; Volume 2, pp. 547-578.

66. Samuelsson, K.; Dumas, J.; Sundman, B.; Lainet, M. An improved method to evaluate the 'Joint Oxyde-Gaine' formation in $(\mathrm{U}, \mathrm{Pu}) \mathrm{O}_{2}$ irradiated fuels using the Germinal V2 code coupled to Calphad thermodynamic computations. EPJ Nucl. Sci. Technol. 2020, 6, 1-12. [CrossRef]

67. Kurata, M.; Osaka, M.; Jacquemain, D.; Barrachin, M.; Haste, T. Advances in fuel chemistry during a severe accident. In Advances in Nuclear Fuel Chemistry; Piro, M., Ed.; Elsevier: Amsterdam, The Netherlands, 2020; Chapter 14, pp. 555-625.

68. Van Uffelen, P.; Hales, J.; Li, W.; Rossiter, G.; Williamson, R. A review of fuel performance modelling. J. Nucl. Mater. 2019, 516, 373-412. [CrossRef]

69. Van Uffelen, P.; Pastore, G. Oxide fuel performance modeling and simulation. In Comprehensive Nuclear Materials, 2nd ed.; Konings, R., Stoller, R., Eds.; Elsevier: Amsterdam, The Netherlands, 2020; Volume 2, Chapter 13, pp. $363-416$.

70. Ogata, T.; Kim, Y.; Yacout, A. Metal fuel performance modeling and simulation. In Comprehensive Nuclear Materials, 2nd ed.; Konings, R., Stoller, R., Eds.; Elsevier: Amsterdam, The Netherlands, 2020; Volume 5, Chapter 2, pp. $43-87$.

71. Verfondern, K.; Nabielek, H. TRISO fuel performance modeling and simulation. In Comprehensive Nuclear Materials, 2nd ed.; Konings, R., Stoller, R., Eds.; Elsevier: Amsterdam, The Netherlands, 2020; Volume 5, Chapter 11, pp. 361-397.

72. Cubicciotti, D. Thermodynamics of vaporization of fission products and materials under severe reactor accident conditions: Analysis of molten core/concrete chemistry. J. Nucl. Mater. 1985, 130, 3-17. [CrossRef]

73. Cubicciotti, D. Vapor transport of fission products under nuclear accident conditions. J. Nucl. Mater. 1988, 154, 53-61. [CrossRef]

74. Olander, D.; Mubayi, V. Review of the Materials-Chemistry Models in the VICTORIA Code. J. Nucl. Mater. 1999, 270, 1-10. [CrossRef]

75. Veshchunov, M.; Dubourg, R.; Ozrin, V.; Shestak, V.; Tarasov, V. Mechanistic modelling of urania fuel evolution and fission product migration during irradiation and heating. J. Nucl. Mater. 2007, 362, 327-335. [CrossRef]

76. Ducros, G.; Malgouyres, P.; Kissane, M.; Boulaud, D.; Durin, M. Fission product release under severe accidental conditions: General presentation of the program and synthesis of VERCORS 1-6 results. Nucl. Eng. Des. 2001, 208, 191-203. [CrossRef]

77. Dubourg, R.; Barrachin, M.; Ducher, R.; Gavillet, D.; Bremaecker, A.D. Fuel and fission product behaviour in early phases of a severe accident. Part II: Interpretation of the experimental results of the PHEBUS FPT2 test. J. Nucl. Mater. 2014, 453, 355-374. [CrossRef]

78. Powers, D.; Brockmann, J.; Shiver, A. VANESA: A Mechanistic Model of Radionuclide Release and Aerosol Generation during Core Debris Interactions with Concrete; Technical Report SAND85-1370; Sandia National Laboratories: Albuquerque, NM, USA, 1985.

79. Piro, M. Computational Thermochemistry of Nuclear Fuel. In Advances in Nuclear Fuel Chemistry; Piro, M., Ed.; Elsevier: Amsterdam, The Netherlands, 2020; Chapter 4, pp. 159-182.

80. Brillant, G.; Marchetto, C.; Plumecocq, W. Fission product release from nuclear fuel I. Physical modelling in the ASTEC code. Ann. Nucl. Energy 2013, 61, 88-95. [CrossRef]

81. Brillant, G. Models for the release from fuel of Ce, La, Sr, and Eu in accident conditions. Prog. Nucl. Energy 2011, 53, 125-131. [CrossRef]

82. Brito, A.; Iglesias, F.; Liu, Y.; Petrilli, M.; Richards, M.; Gibb, R.; Reid, P. SOURCE 2.0: A computer program to calculation fission product release from multiple fuel elements for accident scenarios. In Proceedings of the CANDU Fuel Conference, Pembroke, ON, Canada, 1-4 October 1995.

83. Barber, D.; Parlatan, Y.; Dickson, L.; Corse, B.; Kaye, M.; Lewis, B.; Thompson, W.; Colins, K.; Dickson, R.; Hoang, Y.; et al. SOURCE IST 2.0: Fission product release code. In Proceedings of the CANDU Fuel Conference, Belleville, ON, Canada, 18-21 September 2005.

84. Barber, D. Implementation of a Gibbs energy minimizer in a fission-product release computer program. AECL Nucl. Rev. 2013, 2, 39-48. [CrossRef]

85. Corse, B. Form 2.0: Fuel Oxidation and Release Model. A Computer Code to Predict the Low Volatile Fission-Product Release and Fuel Volatilization from Uranium Dioxide Fuel Under Severe Reactor Accident Conditions. Ph.D. Thesis, Royal Military College of Canada, Kingston, ON, Canada, 1997.

86. Lewis, B.; Corse, B.; Thompson, W.; Kaye, M.; Iglesias, F.; Elder, P.; Dickson, R.; Liu, Z. Low volatile fission-product release and fuel volatilization during severe reactor accident conditions. J. Nucl. Mater. 1998, 252, 235-256. [CrossRef] 
87. Kaye, M.; Lewis, B.; Thompson, W. Thermodynamic treatment of noble metal fission products in nuclear fuel. J. Nucl. Mater. 2007, 366, 8-27. [CrossRef]

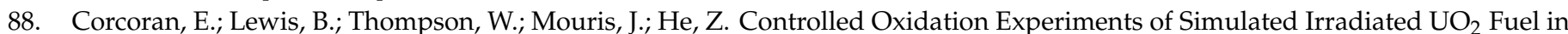
Relation to Thermochemical Modelling. J. Nucl. Mater. 2010, 414, 73-82. [CrossRef]

89. Thompson, W.; Lewis, B.; Corcoran, E.; Kaye, M.; White, S.; Akbari, F.; He, Z.; Verrall, R.; Higgs, J.; Thompson, D.; et al. Thermodynamic Treatment of Uranium Dioxide Based Nuclear Fuel. Int. J. Mater. Res. 2007, 98, 1004-1011. [CrossRef]

90. Piro, M. Thermodynamic Predictions of CANDU Fuel Volatilization and Fission Product Behaviour Under Severe Accident Conditions. J. Nucl. Mater. in-review.

91. Geiger, E.; Guéneau, C.; Corcoran, E.; Piro, M. Thermodynamic investigations of fuel-cladding chemical interaction in U-5Fs and U-10Zr metallic fuels with the TAF-ID. J. Nucl. Mater. 2021, 551, 152981. [CrossRef]

92. Magni, A.; Nevo, A.D.; Luzzi, L.; Rozzia, D.; Adorni, M.; Schubert, A.; Uffelen, P.V. The TRANSURANUS fuel performance code. In Nuclear Power Plant Design and Analaysis Codes; Wang, J., Li, X., Allison, C., Hohorst, J., Eds.; Elsevier: Amsterdam, The Netherlands, 2020; Chapter 8, pp. 161-205.

93. Kleykamp, H. The chemical state of the fission products in oxide fuels. J. Nucl. Mater. 1985, 131, 221-246. [CrossRef]

94. Cheynet, B.; Fischer, E. MEPHISTA: A Thermodynamic Database for New Generation Nuclear Fuels; Technical Report hal-00222025; Thermodata-INPG-CNRS: Saint Martin d'Hères, France, 2007.

95. McMurray, J.; Besmann, T.; Ard, J.; Fitzpatrick, B.; Piro, M.; Jerden, J.; Williamson, M.; Collins, B.; Betzler, B.; Qualls, A. Multi-Physics Simulations for Molten Salt Reactor Evaluation: Chemistry Modeling and Database Development; Technical Report ORNL/SPR-2018/864; Oak Ridge National Laboratory: Oak Ridge, TN, USA, 2018.

96. Piro, M.; Simunovic, S. Performance Enhancing Algorithms for Computing Thermodynamic Equilibria. Calphad 2012, 39, 104-110. [CrossRef]

97. Piro, M.; Simunovic, S. Global optimization algorithms to compute thermodynamic equilibria in large complex systems with performance considerations. Comput. Mater. Sci. 2016, 118, 87-96. [CrossRef]

98. Ni, X. Nuclear engineering software quality assurance. In Nuclear Power Plant Design and Analaysis Codes; Wang, J., Li, X., Allison, C., Hohorst, J., Eds.; Elsevier: Amsterdam, The Netherlands, 2020; Chapter 3, pp. 55-74.

99. Piro, M.; Besmann, T.; Simunovic, S.; Lewis, B.; Thompson, W. Numerical verification of equilibrium thermodynamic computations in nuclear fuel performance codes. J. Nucl. Mater. 2011, 414, 399-407. [CrossRef] 